\title{
خطاب الكراهية في نطاق الفقه واجتهادات المحاكم الجنائية اللدولية
}

أ.م. د. أحمد عبيس نعمة الفتلاوي

جامعة الكوفة- كلية القانون 
ركز البحث على بيان مفهوم خطاب الكراهية في نطاق الفقه والاجتهاد القضائي للدحاكم الجنائية الدولية وبالذات الدكمة الجنائية الدولية ليوغسلافيا السابقة والمحكمة الجنائية الدولية لرواندا، فضلاً عن المحكمة الجنائية الدولية، ومقارنة ما ذهبت إليه الأخيرة مع توجهات الفقه والاجتهاد القضائي على المستوى الوطني، إذ حاول البحث الوقوف على إثكالية الاختلاف في التوجهات الفقهية من جهة ومواقف المحاكم الجنائية الدولية من جهة أخرى، وبالتحديد في موضوع تكييف خطاب الكراهية كجريمة مستقلة بحد ذاتها، أم في تكيفهها كسلوك لا يمكن عدّه جريمة، إلا في حالة ارتكاب جريمة دولية أسهم خطاب الكراهية على وقوعها.

Abstract

The Article will examine the position of Hate Speech in international criminal law, within two sections: the first one shed light on the linguistic and terminological concept of term of Hate Speech, as well as looks at hate speech effects in scope of the periods of war and peace.

The second section will focus on Hate Speech and whether occupied to the ranks of abnormal and criminal behaviors, in the two sub-sections: first looks at the legal qualification (the level of national and regional efforts), while the second will search on International Criminal Courts Jurisprudences, so as to answer the following question: what is the reason of differences treatment of Hate Speech in Statutes of International Criminal Courts? Why some of them adopted Hate Speech as a Criminal behavior in itself, while the other tended to adapt it as a non- dependency crime in itself. 
ما من شك في أن لغة الحوار الايجابية والقائمة على التسامح بين بني البشر، ستسهم في تذليل أية تحديات تعيشها مجتمعات نتوعت فيها القوميات والأعراق وغيرها من العوامل غير المتجانسة، ولكن وللأسف ما زال قسم كبير من البشرية تعيش وبفعل خلافات تاريخية أو معتقدات سواء أكانت حقيقية أم من صنع المستعمر تصنع حاجزا للتعايش بسلام ، ولتحصد رلهد أرواحا بين الفينة والأخرى، وليكون خطاب الكراهية السلاح والأداة في إذكاء نار الفتتة ولتبث روح الانتقام بين بني البشر • ولأجل ذلك سيحاول البحث في اختبار موقف القانون الجنائي الدولي من خطاب الكراهية، وفي مبحثين يسلط الأول الضوء على المفهوم اللغوي والاصطلاحي من جهة، فيما ييحث الثاني في نطاق الآثار المترتبة على خطاب الكراهية في فترتي السلم والحرب. أما المبحث الثاني فسيركز على موضوع خطاب الكراهية وهل ارتقى لمصاف السلوكيات غير السوية والمُجرّمة، وذللك في مطلبين: الأول نبحث فيه التكييف القانوني على مستوى الجهود الوطنية والإقليمية، أما الثاني فسيبحث في موقف المحاكم الجنائية الدولية ولنجيب على الإثكالية التالية: ما سبب التباين والاختلاف في النظم الأساسية للمحاكم الجنائية الدولية بشأن جريمة خطاب الكراهية؟ وبعبارة

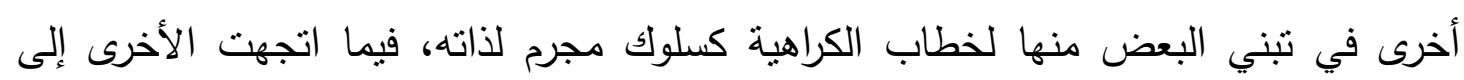
تكييفه كجريمة ملحقة وتبعية لجرائم أخرى.

\section{المبحث الأول: مفهوم خطاب الكراهية في فترتي السلم وإلحرب}

ما هو مفهوم خطاب الكراهية في ضوء التشريعات الجزائية الوطنية والصكوك الدولية ؟ وكيف

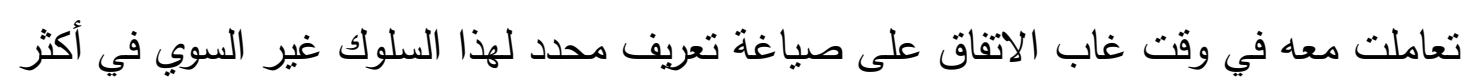
الاتفاقيات الدولية ؟ ما هي الحدود الفاصلة بين الحق في التعبير وبين الحق في عدم التعدي على المبادئ الإنسانية ؟ كل ذللك سنحاول الإجابة عنه في مطلبين سيركزان على بيان مفهوم خطاب الكراهية من جهة، ونطاقه في فترتي السلم والحرب من جهة أخرى. 


\section{المطلب الأول: مفهوم خطاب الكراهية}

سيبحث المطلب في مفهوم خطاب الكراهية، وذللك في فرعين الأول يتطرق إلى المفهوم اللغوي و الاصطلاحي، فيما سيركز الآخر على بيان الحدود الفاصلة بين مفهومي خطاب الكراهية والحق

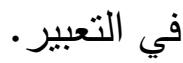
الفرع الأول: خطاب الكراهية في اللغة والاصطلاح لبيان مفهوم خطاب الكراهية سنشرع في البحث عنه في اللغة، فضلاً عن آراء الفقهاء واجتهادات المحاكم الجنائية الوطنية والدولية. ففي النطاق اللغوي يشير تعبير خطاب الكراهية إلى كلمنين وهما خطاب: و معناه مراجعة الكلام وقد خاطبه بالكلام مخاطبة وخطاباً وهما يتخاطبان، ويشير أيضاً إلى معنى الرسالة الموجهة إلى هُهي الغير وسواء أكانت كتابة أم لفظاً فيوجهه المخاطب إلى الغير عن قصد ودراية.' أما مصطلح الكراهية فيرجع إلى مصدره وهو الكره، و هو ضد المرغوب فيه، وقيل في ذلك:

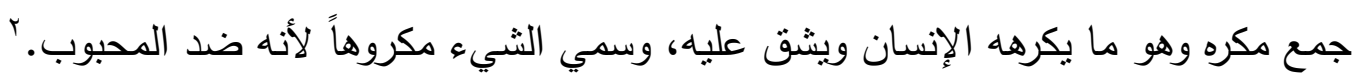
وفي اللغة الانكليزية فيشير مصطلح خطاب الكراهية المكون من كلمتين (Hate: Speech) إلى خطاب يوجه بهدف التهديد أو الإهانة لثخص أو مجموعة على أساس الأصل القومي أو

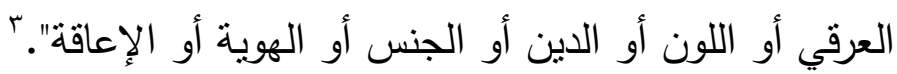
فيما يعرفها قاموس كامبردج بالقول : خطاب عام يعبر عن الكره والتحريض نحو العنف اتجاه شخص أو مجموعة تابعة لعرق أو دين وغيرها".؛ أما التعريف الاصطلاحي فإنه ورغم الاتفاق الواسع النطاق على أن خطاب الكراهية هو ذلك

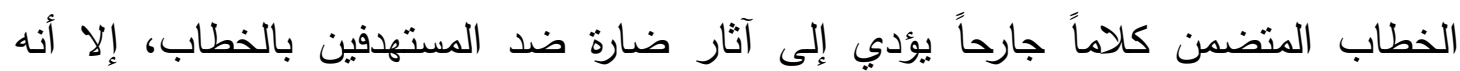
مصطلح غير متفق عليه اصطلاحاً، و تأكيداً على ذلك يثير تقرير للمفوضة السامية لحقوق الإنسان، ييين فيه أن محاولات عدة لتعريفه باءت بالفشل، فعلى سبيل المثال تجنبت لجنة حقوق الإنسان التابعة للأكم المتحدة تعريف خطاب الكراهية، وبدلا عن ذلك ذهبت إلى تعريف الأذى المحتمل لهذا النوع من التعبير على حقوق الغير.• وفي الثأن الفقهي لتعريف خطاب الكراهية، فقد ذهبت يوليا تيموفيفا (Yulia A. Timofeeva) إلى المعنى الوارد في قاموس بلالك القانوني بأنه: " خطاب يحمل معاني للتعبير عن الكراهية

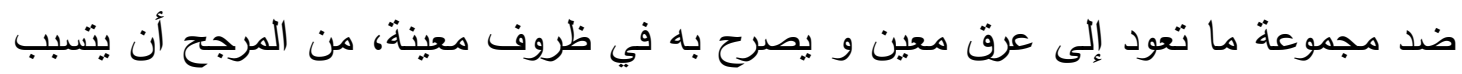


بإثارة العنف منبادل"، وفي معنى آخر بأنه:" شكل من أثكال التعبير المهاجم لهجموعات أو أقليات أثثية أو دينية ، كما يعرف بأنه خطاب يتضمن توجيه رسالة للآخرين عن الكراهية

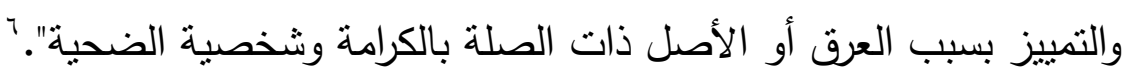
فيما اتجهت نقابة المحامين الأمريكيين إلى تعريفه بالقول : "الخطاب الذي يسئ أو يهدد أو يهين

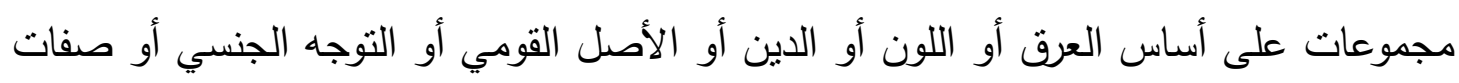

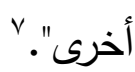
وقد عرفتها زليخة أبو ريشة بأنها :" كل كلام يثثر مشاعر الكره نحو مكون أو أكثر من مكونات

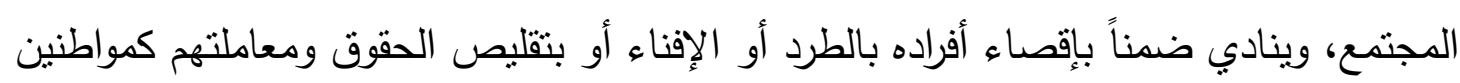
من درجة أقل". وأخيراً وعلى مستوى الاجتهادات القضائية، فقد أنشارت المحكمة الجنائية الدولية لرواندا في قضية ناهيمانا (Nahimana) إلى تنيان مفهوم خطاب الكراهية بأنه:" شكل من أنثكال العدوان التمييزي الهادف إلى تدمير كرامة الإنسان ومهاجمة المجموعة". 9 وبناءً على ما تقدم من تعريفات، فأن خطاب الكراهية لا يبعد أن يكون منهج يقوم به شخص أو أو

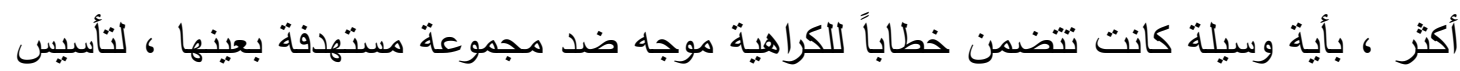
فكر منطرف يهدف في النهاية إلى الترويج للقضاء على تللك المجموعة. الفرع الثاني: خطاب الكراهية في ضوء الحق في التعبير من المسائل المتفق عليها أن يكون الثخص حراً في التعبير عن وجهة نظره، ولكن هل من فن

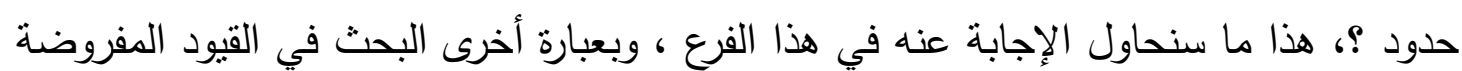
على الحق في التعبير . لقد أثنارت عدة صكوك دولية إلى الحق في التعبير، ومنها الإعلان العالمي لحقوق الإنسان في

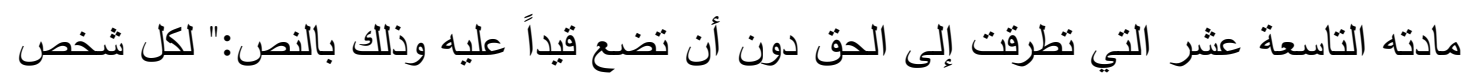
الحق في حرية الرأي والتعبير ويشمل هذا الحق حرية اعتتاق الآراء دون أي تدخل واستفتاء الإنباء والأفكار وتلقيها وإذاعتها بأية وسيلة كانت دون تقيد بالحدود الجغرافية". ' أما الاتفاقية الأوربية لحقوق الإنسان فقد كانت أكثر دقة من حيث الصياغة والوضوح في التمييز بين الحق في التعبير وبين مخاطر هذا الحق إذا مورس على نحو يثير الكراهية بين أفراد المجتمع ، إذ نصت الفقرة (1) من المادة (9) منها على الحق في التعبير بالنص :" لكل إنسان 
الحق في حرية التعبير ....."، أما الفقرة (r) من المادة نفسها فقد وضعت قيود على ذلك الحق بالنص :" هذه الحريات تتضمن واجبات ومسؤوليات لذا يجوز إخضاعها لشكليات إجرائية وشروط وقيود وعقوبات محددة في القانون ... لصالح الأمن القومي وسلامة الأراضي وأمن

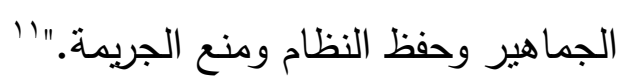
أما الاتفاقية الأمريكية لحقوق الإنسان فقد تطرقت إلى المضمون نفسه الوارد في الاتفاقية

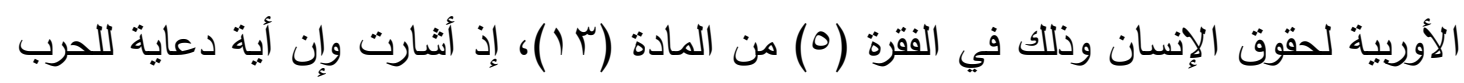
وأية دعوة إلى الكراهية القومية أو الدينية واللذين يشكلان تحريضاً على العنف الدخالف للقانون

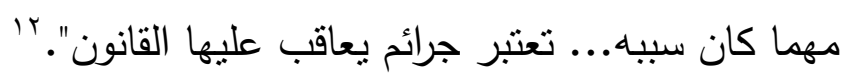

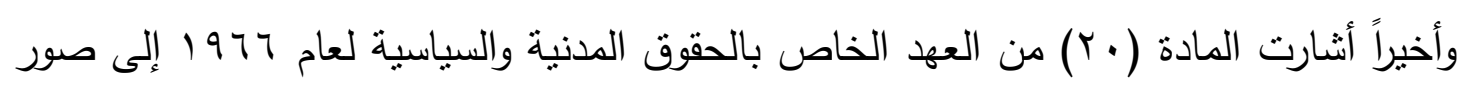
خطاب الكراهية بالنص:" تحظر بالقانون أية دعاية للحرب،r. تحظر بالقانون لأية دعوة إلى

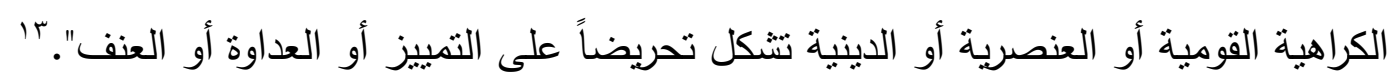
ويمكن القول إن التعريف الرسمي الوحيد المعتد حالياً في بيان خطاب الكراهية ، ما نجده في النياني

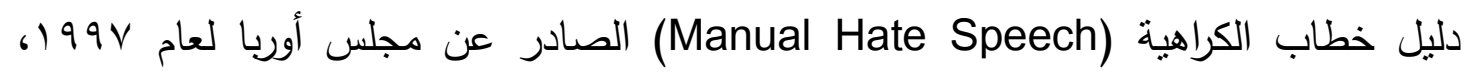
والذي عرفه بأنه :" وكما يفهم بأنه مصطلح يغطي أنثكال التعبير كافة الموسعة للتحريض

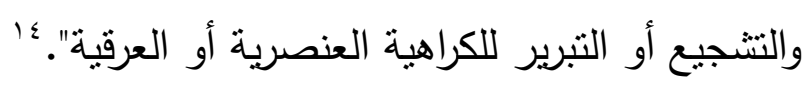
أن اختلاف وجهات النظر بين المؤيدين لحرية التعبير المطلقة من جهة، وبين المؤيدين إلى إنى وضع قيود عليها، لا يزال قائماً، وبعبارة أخرى هنالك من يؤيد وضع قيود على حرية التعبير إذا

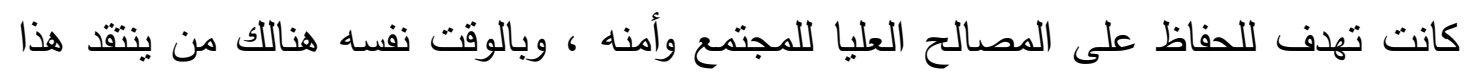
التوجه على أساس انه سيقوض البحث عن الحقيقة في مسألة ما ، ومن ثم الحق في التعبير عنها".

أن جوهر القيد المفروض على حرية التعبير يلخصها تيمرمان ( Kibka Kristin

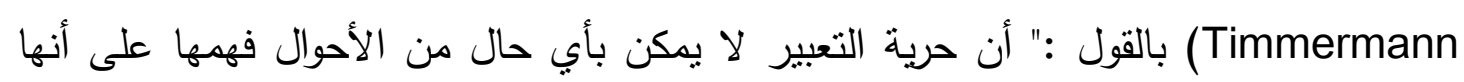
حق في تحريض الأفراد على ارتكاب جريمة". 17 وبلا أدنى شك يمكن القول إن الموضوع يتصل بأمر غاية في الأهمية وهي الموازنة بين الحق الحقاب في التعبير وبين المصالح المهددة بسبب هذا الحق، وبعبارة أخرى فأن أي مصلحة معقولة يحتمل و على نحو مقنع بأنها ستتعرض إلى الانتهاك ، فإن (الحق) في التعبير سيكون موقوفاً 
ومحظورأ حينها، وهو ما أثنارت إليه الدراسة المعنية بالمعايير الدولية ذات الصلة بالتحريض أمات على ارتكاب الإبادة الجماعية أو الكره العنصري، التي أعدها المستشار الخاص للأمم المتحدة

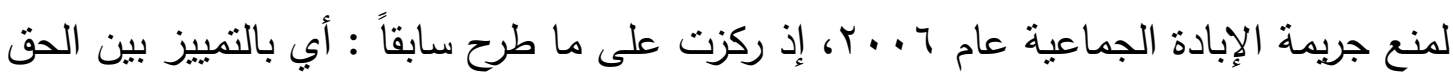

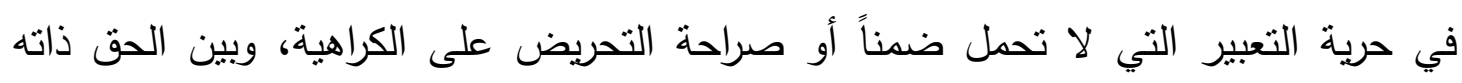

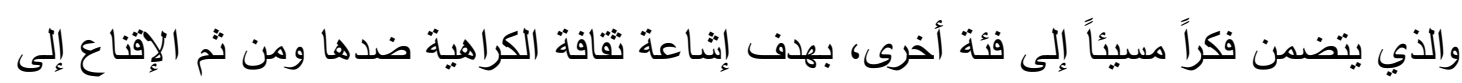

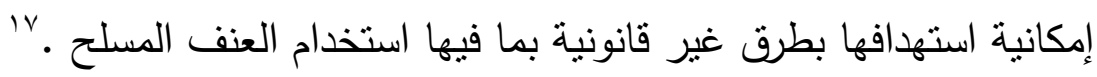
وعليه فإن كان الخطاب لا يتضمن صراحة أو ضمناً، ما يدعو إلى الكراهية وانتهاك مبادئ إنسانية، فلا يمكن عدّهُ خطاباً للكراهية يستلزم قيام المسؤولية و أن التوجه القضائي الدولي في هذا الصدد يؤيد ما تقدم، فعلى سييل المثال قضت المحكمة الأوربية لحقوق الإنسان قي قضية

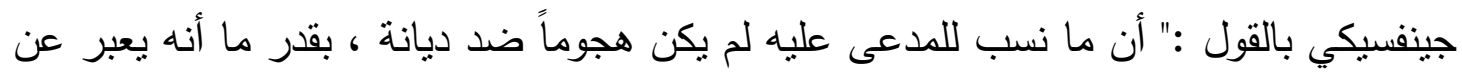

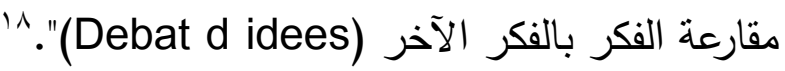
المطلب الثاني: خطاب الكراهية في السلم والحرب بداية نسأل: ما هي الآثار المترتبة على خطاب الكراهية ؟ و هل يلزم لقيام المسؤولية أن يقع خطاب الكراهية في فنرة السلم أم الحرب أم الاثنان معاً؟ هذا ما سنحاول الإجابة عنه من خلال تقسيم المطلب إلى فرعين وعلى النحو الآتي: الفرع الأول: خطاب الكراهية في زمن السلم إن المخاطر الملازمة لخطاب الكراهية في وقت السلم تبدو ملامحها في تهيئة وتعبئة مجموعة ضد مجموعة أخرى لأجل إلحاق الأذى فيها في وقت السلم، ويجمع عدد من الباحثينج" بأن جريمة الإبادة الجماعية هي المحصلة الكبرى والنتيجة المتوقعة من هكذا خطابات، و ذلك بالاستتاد إلى نص الفقرة (ج) من المادة الثالثة من اتفاقية منع الإبادة الجماعية والمعاقبة عليها

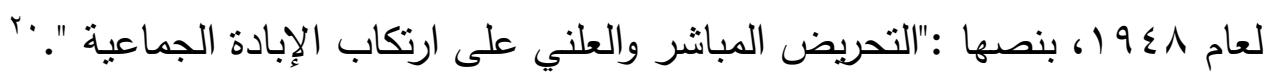
ولكن ما هي وسائل هذه التعبئة ؟ وما هو محتواها ؟ للإجابة نقول أن الوسائل التي يمكن من خلالها بث خطاب الكراهية متتوعة و مختلفة في التأثنر ، فقد تكون بخطاب يلقى مباشرة أمام الجمهور أو من خلال أية وسيلة إعلامية أخرى. وهو ما لمابل بمكن الاصطلاح عليه بدعاية الكره (Hate Propaganda)، المتضمنة لأفكار وتصورات تثير الكراهية ضد الآخرين، وقد تحتاج لفترة لأجل الإفناع والاحتواء عند المخاطبين ومن ثم الوصول 
إلى الهدف هذا، أي أن يتم إعداد طرف كاره لطرف آخر، لدرجة يمكن وفي أية لحظة تتهيأ الظروف لارتكاب الجريمة بدافع طائفي أو عرقي أو غير ذلك. ومن جهة أخرى فإن محتوى هذه الدعاية يتضمن ما يمكن الاصطلاح عليه بالكره المبني على على عائ

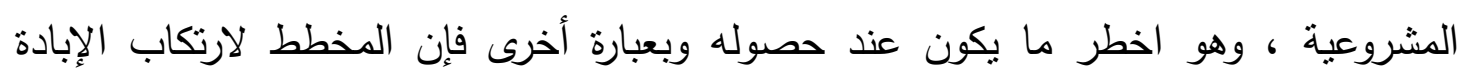

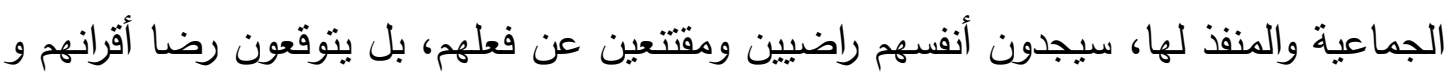
رضا الطائفة و العرق الذي ينتمون إليه. وفي هذا الثأن تصور لنا ويبكي تيمرمان (Wibke Kristin Timmermann) بالقول :" إن مثل هذه الدعاية ستكون أكثر خطورة من أي تحريض آخر مباشر على ارتكاب الإبادة الجماعية ، إذ أن الأخيرة لا ترتكب في العادة، إلا إذا سبقها تصور ذهني ينشأ قبل ارتكاب الإبادة

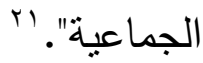

وبما أن جريمة الكراهية تقوم على دوافع محددة قد يكون فيها (المنفذ) غافلاً عن النية الني يختبئ وراءها أنثخاص آخرون (المحرضون)، بل وقد يكثف عن حقيقة ما وراء تلك الفظائع وهو ما يصوره لنا ماركو ساسولي بقوله:" أن البحث في أسباب الجرائم الدولية وبالذات الواسعة

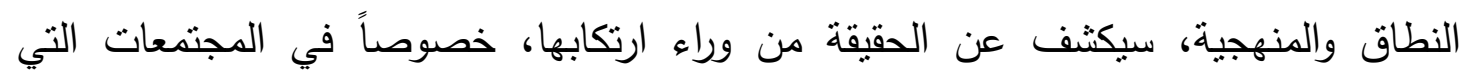
توصف بأنها غير متجانسة بالأصل أو غير متجانسة لأسباب واهية ومختلفة صنعتها الدول الاستعمارية لتؤسس لها إثاعة الكراهية الأرض المناسبة لتوغلها في نفوس من نفذ تلك

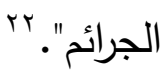

ومن أجلى الوقائع التي تدعم ما طرحنا سابقاً، ما ذكره المؤرخ في الثأن الإفريقي جان بيار كرتيان أمام المحكمة الجنائية الخاصة برواندا، حينما استدعته الأخيرة لشرح الأسباب الحقيقية من وراء الإبادة الجماعية الني وقعت بين الهوتو والنوتسي، إذ بين كرنيان بالقول :" أن مسألة

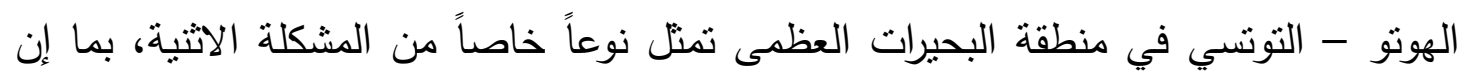
الهوتو والتوتسي ليسا شعبين غير متجانسين تجمعا ضمن حدود مصطنعة....، ثم يضيف ..." وبدلاً من أن يقوم الحكم الاستعماري البلجيكي منذ عام 1190 ، لمنطقة البحيرات العظمى لهيل بممارسة سياسة فرق نسد كانت الإدارة الاستعمارية نستتد إلى أيدلوجية عدم مساواة عرقية حرضت التونسي الذين كانوا يعاملون كارستقراطيين حقيقيين ضد الهونو الذين كانوا يعتبرون

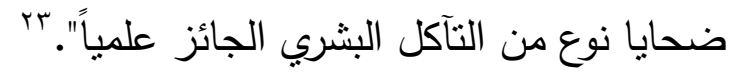


وختم كرتيان هذه الحقائق بنتيجة منطقية بقوله :" وبما أنه يمكن التنرع بتنبؤات الخوف الذي

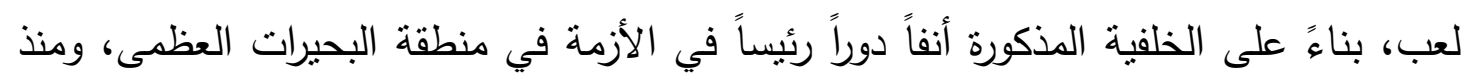
عام 1909 فصاعداً فقد كان الخوف هو القوة التكتيكية الأساسية الدافعة للتعبئة الثنعبية أثناء

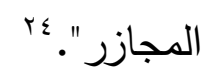

وخلاصة القول إن خطاب الكراهية ولكي يكون مُجرّماً في وقت السلم، لابد أن يتوافر فيه شرط

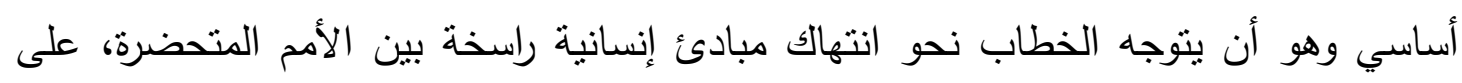
سبيل المثال التحريض على الكراهية ضد قومية أو عرق، لكونها سترسخ الانقسام بين بني البشر وتعمق الكراهية لدرجة يمكن أن تصل إلى إفناء الآخر والقضاء عليه في أي لحظة ينشب فيها خلاف ،وبعبارة أخرى أن يتطور من مجرد نوتر طائفي أو عرقي إلى حالة من النزاع المسلح غير الدولي في أغلب الأحيان. أما إذا كان خطاب الكراهية يوجه ضد أثخاص أو مجموعات بالفعل ارتكبت تصرفات لان النانه إنسانية فلا يتصور أن تقع الجريمة، إذ هي تأخذ صورة الإدانة والاستتكار المجرد من أي نشاط لئاط

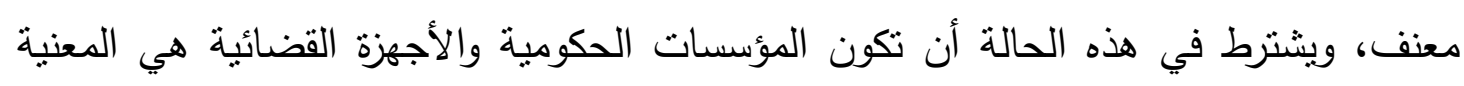

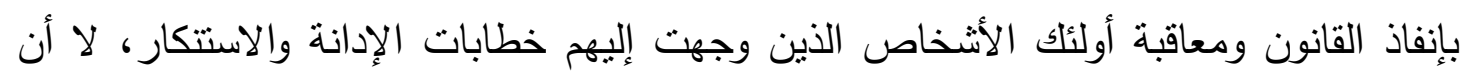
يكون ذلك عن طريق انتقام ومعاقبة يقوم بها الأفراد خارجاً عن الإطار المؤسسي والقانوني لأي الإدي دولة تشهد مثل هكذا أوضاع. الفرع الثاني: خطاب الكراهية في إثناء النزاعات المسلحة قد يتبادر إلى الذهن السؤال الآتي: هل من حدود في خطاب الكراهية بين الأطراف المتعادية في

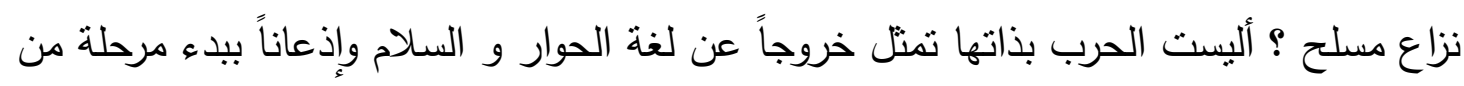
الكره والعداء للطرف الآخر؟ هذا ما سنحاول الإجابة عنه في هذا الفرع. أن خطاب الكراهية في النزاعات المسلحة ليس وليد عصرنا الراهن، إذ يقدم لنا كريكوري جولدن (Gregory S .Gordon)

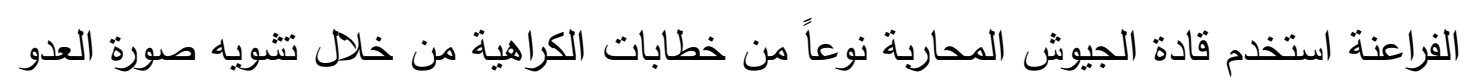
في أعين الجنود قبل إرسالهم إلى المعركة، إذ يصور أولئك القادة خصومهم بالحشرات القذرة

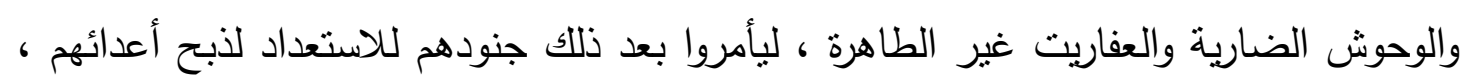

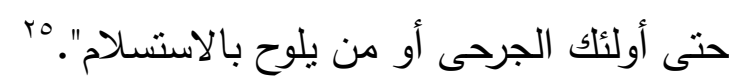


أن بث الكراهية ضد العدو وعدم الرحمة به يصوره كذلك جان بكتيه بقوله :" فانتصار الأقوى أو الأمكر ستتبعه مذابح رهيبة وأعمال وحشية لا يمكن وصفها ، وقانون الثرف يمنع المحاريبن

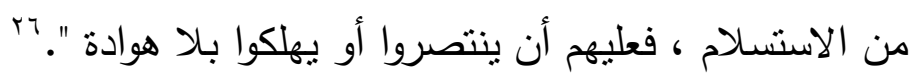
و وفق ما تقدم يمكن القول أنه و على عكس ما تقدم في الفرع الأول، فقد يكون خطاب الكراهية

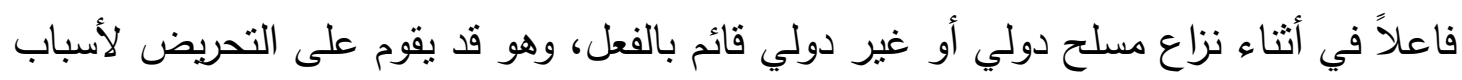
طائفية أو عرقية كنتيجة منطقية لما ذكرناه سابقاً أو لأسباب انتقامية آنية، كأن بأمر قائد للجيش أو مسؤول سياسي علناً بالرد على عمليات قتالية وجهت إلى مدنيين تابعين له، برد مماتل يطال مدنيين الطرف الآخر، وفي هذا الثأن يقسم كريكوري جوردن (Gregory S .Gordon)

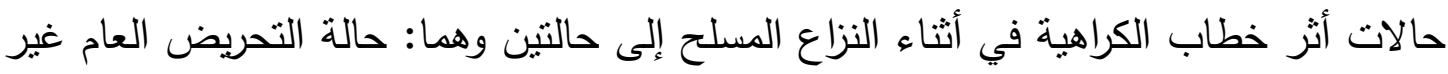
البباثر (Public Component)، وتنطوي على توجيه نداءات مباشرة إلى الجمهور عن طريق الخطابات الموجهة عبر الإذاعة أو الصحافة للتحريض على ارتكاب جرائم ضد الإنسانية، وهي حالة تكثف عن مضمون أكثر انساعاً، بستهفف الجمهور عامة سواءً أكانوا مدنيين أم مقاتلين لأجل التحرك نحو ارتكاب تصرفات غير إنسانية ضد الطرف الدعادي الآخر ، وهي فرضية يؤكل وجودها جيمس هيوجس (James Hughes) بالقول :" أن الإبادة الجماعية سواء ارتكبت

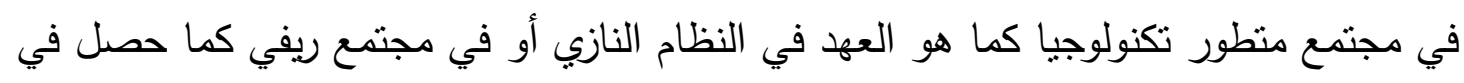
رواندا، إنما ينطلب تعبئة جماهبرية، تسمح بانخراط الأفراد العاديين وبمساعدة الدولة على الى لئي

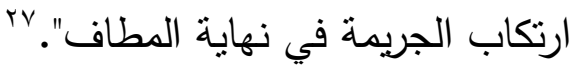

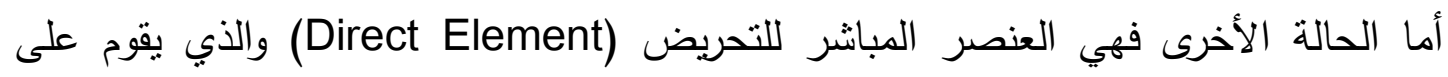

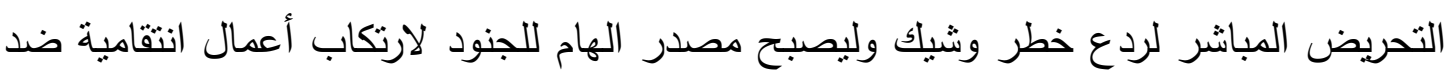

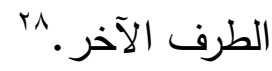

و من جانبه بركز كريكوري جوردن على مصطلح التحريض في أثناء النزاع المسلح، فيقول :" من الممكن أن تؤدي الخطابات التي يلقيها القادة قبل تتفيذ هجوم ما أو في أثناءه إلى ارتكاب التياب فظائع ضد الددنيين، وبعبارة أخرى يمكن أن تؤدي نلك الخطابات إلى ترسيخ قناعة في مخيلة

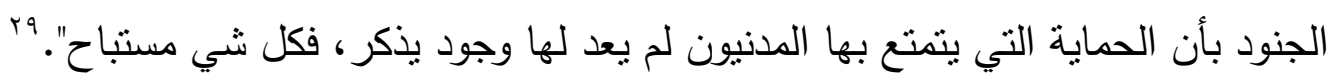
وفيما يخص موقف القانون الدولي الإنساني من استخدام إثناعة خطاب الكراهية في النزاعات

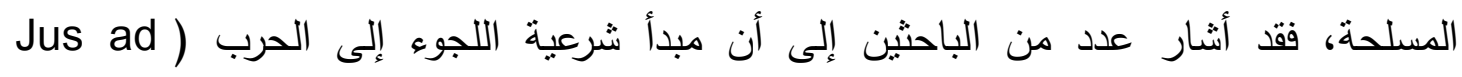


(Bellum

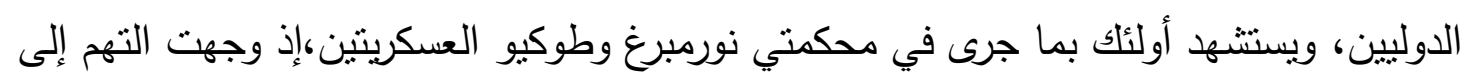

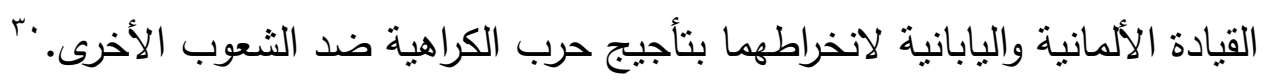

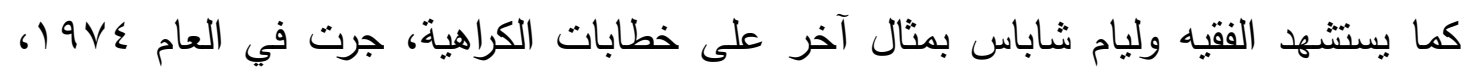
حينما قامت القوات الاندونيسية باحتلال تيمور الثرقية المستتد إلى تحريض من الرئيس

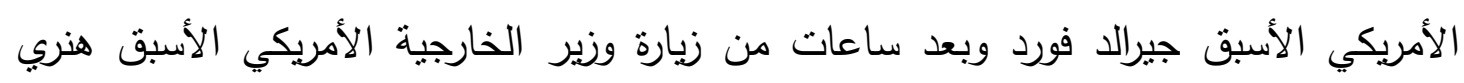

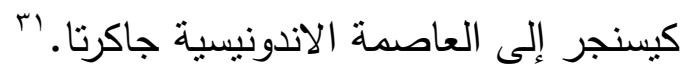
أما قواعد القانون الدولي الإنساني أخرى ذات الصلة بمبدأ سلوكيات الحرب (Jus ad Bello) فمن الممكن أن نجد لخطاب الكراهية نصاً صريحاً يحظر استخدامه ، إذا كان صادراً عن قيادة

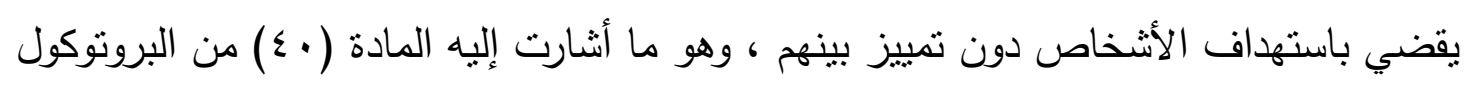

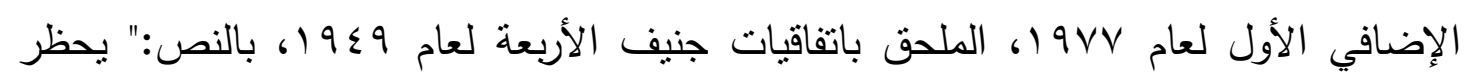

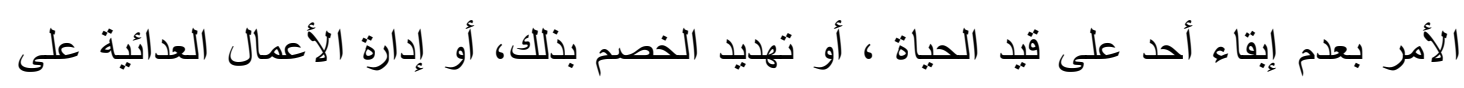

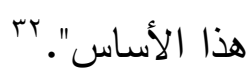
و وفقاً لهذا التصور فمن المكن عدُ خطاب الكراهية المؤدي إلى شن حروب بين الدول بمثابة

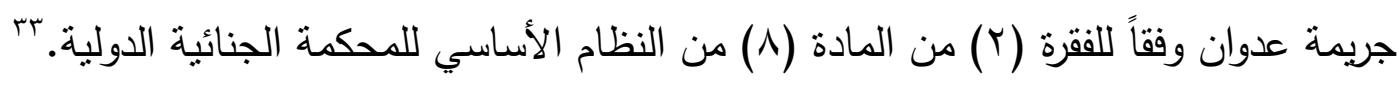
المبحث الثاني: تكييف القانون الجنائي بشأن خطاب الكراهية نحاول في هذا المبحث بيان التكييف القانوني لخطاب الكراهية وعلى المستويين الجنائي الوطني والإقليمي من جهة، والقانون الجنائي الدولي من جهة أخرى، وللإجابة عن سؤال جوهري ينلخص بالآتي: كيف تصدت التشريعات الجزائية والصكوك الدولية الإقليمية لمسألة خطاب الكراهية ؟ هل اتبعت النظم الأساسية للححاكم الجنائية الدولية المنهج ذاته، القائم على عد لإنهائه خطاب الكراهية كجريمة مستقلة أم موقوفة وتبعية على تحقق جرائم أخرى. المطلب الأول: موقف القانون الجنائي الوطني والإقليمي بما أن آثار خطابات الكراهية ستكون اقرب وقعاً على المستوى الوطني والإقليمي منه على لإنى مستوى المجتمع الدولي ككل، سنبحث أولاً في الجهود التي بذلت على هذين المستوبين لمكافحة النطرف في الخطاب وموقف القوانين والاتفاقيات الدولية على المستوى الإقليمي منه. 


\section{الفرع الأول: التثريعات الوطنية}

من أهم الإثكاليات القانونية التي تواجه المختصين في الحقل الجنائي هو في التكييف القانوني لخطاب الكراهية ، إذ أن الخطاب بذاته هو من الأفعال المعنوية التي يصعب إنباتها لارتباط الأمر بنية صاحب الخطاب ، ومن ثم لا يكفي الحكم على محتوى التعبير من ظاهره ، بل لابد من إثبات توجهه في إطار العلم والإرادة نحو تحريض الآخرين بارتكاب جريمة ضد طرف آخر وعلى نحو يتسم بالكراهية الثمولية (Comprehensive Hate) . وهنا يتبادر إلى الذهن السؤال الآتي: ما هو التكييف القانوني لخطاب الكراهية، خصوصاً وانه يجسد حالة ذهنية لا يمكن إثبات نبة فاعلها بسهولة؟ للإجابة نقول: أن عدّ خطاب الكراهية كجريمة مستقلة بذاتها يتطلب توافر ركنين: الأول مادي

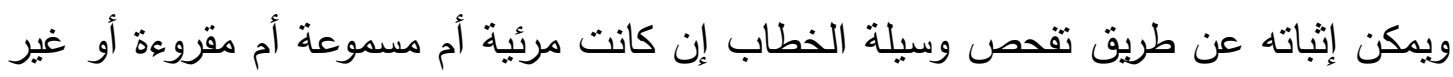
ذللك ، بهدف نسبة الخطاب إلى المتهم، وركن معنوي ويتضمن نية المتهم واتجاهها إلى مهاجمة آخرين بخطاب مع الإدراك والعلم باليقين أو بالاحتمال إلى أن يؤدي ذللك الخطاب إلى إثارة

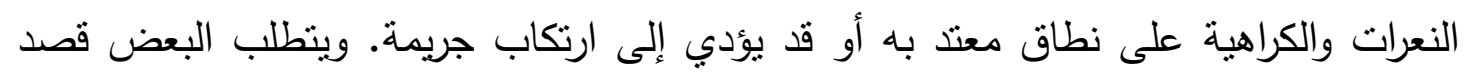
خاص لتجريم هذا السلوك، وهو أن يقصد الجاني من خطابه توجيه رسالة إلى المخاطبين

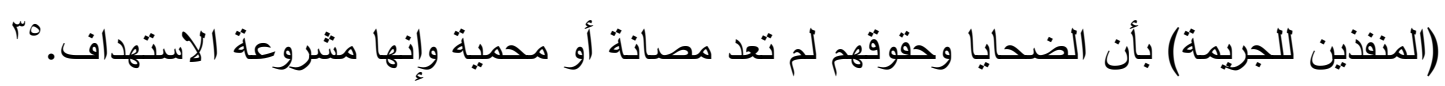
وفي هذا الثأن يشير القاضي الأسبق انطونيو كاسيزي بالقول :" تتسم الجرائم الدولية بميزتين أساسيتين نكمن الأولى في الأفعال المادية وأخرى معنوية ويعنى بها القصد أن يودي بحئ النياة

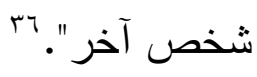

لقد أثنار كل من أحمد عزت و فهد البنا و نهاد عبود إلى عناصر موضوعية مهمة لتحديد طبيعة خطاب الكراهية ، وذلك من خلال توافر العناصر الآتي ذكرها: أ-سياق الخطاب: وهنا لابد من التركيز على وجود مضمون تعبيري يصرح به شخص ذا مكانه

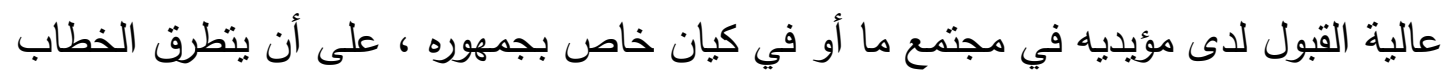

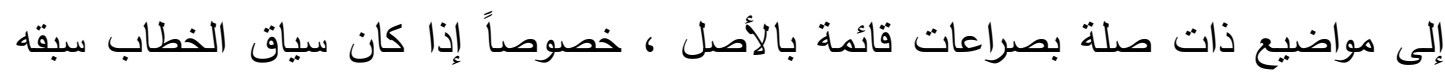

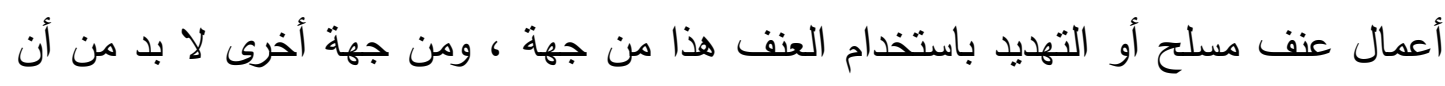
يتوقع وعلى نحو معتد به بأن منل هكذا خطابات ستسهم في قيام ردة فعل مقابلة ، لا تشهد 
إدانة اجتماعية إن وقعت ، بسبب ما يتضمنه الخطاب الموجه والخطاب المقابل له من الطرف الآخر المستهدف من عبارات الكراهية المفضية إلى العنف في اغلب الأحيان.

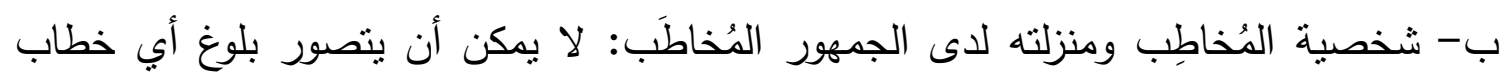

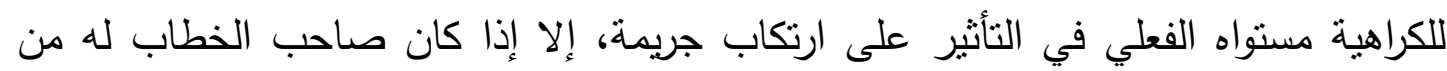

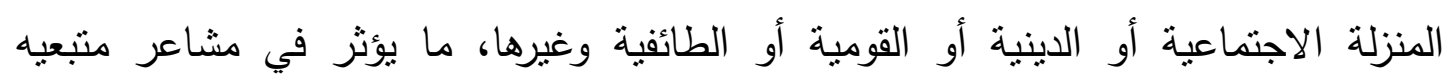
ومؤيديه ويدفعهم إلى تتفيذ ما تلقوه من مضامين تدعو إلى الكراهية. ت- نية الفاعل: وهنا يمكن الاستخلال على النية من خلال ثلاثة عناصر وهي: اتجاه العلم والإرادة

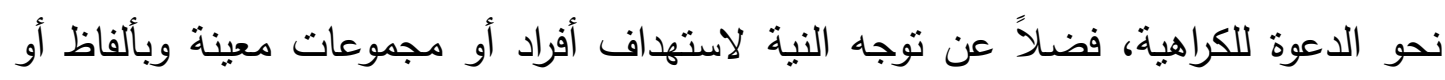
تعبيرات صريحة أو مبطنة، وأخيراً الإدراك والوعي بما قد يترتب على خطاب الكراهية من لنه نتائج.

أما بخصوص تكييف الجرائم الناجمة عن خطاب الكراهية فقد دأبت معظم التشريعات الجزائية الوطنية على التصدي لأي تصرفات من شأنها زعزعة الاستقرار داخل المجتمعات وخصوصاً المتعددة الأعراق والمذاهب الدينية، ومن ضمن التتريعات تلك ما نجده راسخاً في المادة (190) من قانون العقوبات العراقي رقم (11) لسنة 1979 (1) والتي نصت على:" بعاقب بالسجن المؤبد من استهدف إثارة حرب اهلية أو اقتتال طائفي وذذلك بتسليح المواطنين او يحملهم على التسلح بعضهم ضد البعض الآخر او الحث على الاقتتال وتكون العقوبة الاعدام إذا ما تحقق ما استهدفه الجاني"، و في الفقرة (Y) من المادة (99 (1) من القانون نفسه نصت :" ويعاقب بالعقوبة القات ذاتها : كل من حرض ... أو حبذ أو روج ما يثير النعرات المذهبية أو الطائفية أو حرض على الى

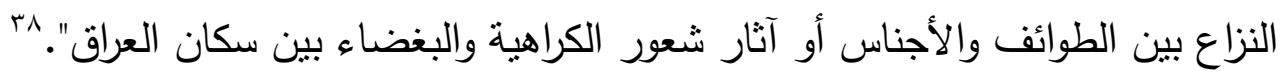

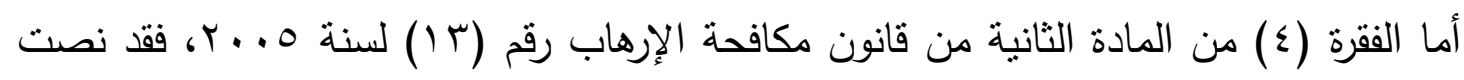
بأنه:" العمل بالعنف والتهديد على إثارة فتتة طائفية أو حرب أهلية أو اقتتال طائفي وذلك بتسليح

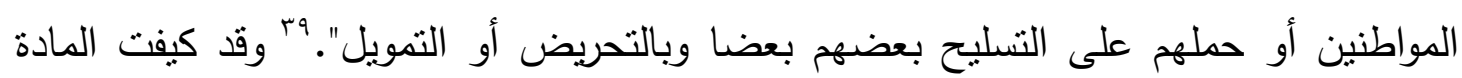

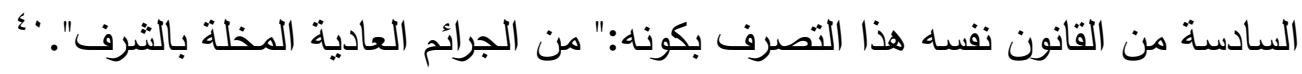
وقد أخذت بعض التشريعات الجزائية العربية صراحة الاتجاه القائم على تجريم خطاب الكراهية

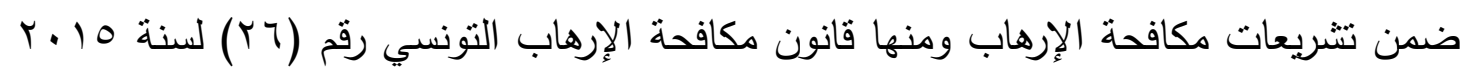


في البند ثامناً بالنص:" التكفير أو الدعوة إليه أو التحريض على الكراهية أو التباغض بين

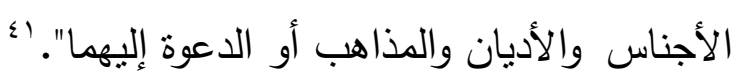
و بالنسبة للتشريعات الجزائية الأخرى، فعلى سبيل المثال ميز القانون الانكليزي بين ثلاثة حالات ذات صلة بجرائم الكراهية إذ وصفت بالجرائم المشددة العقوبة (Aggravated Crimes)، وهذه الجرائم هي الاعتداء القائم على أساس غير عنصري وفقاً للقانون رقم (7/91 ()، و جريمة إثارة الكراهية على أساس العرق أو الدين، أما الأخيرة فهي الجرائم القائمة على العداء العرقي أو أو أوناء

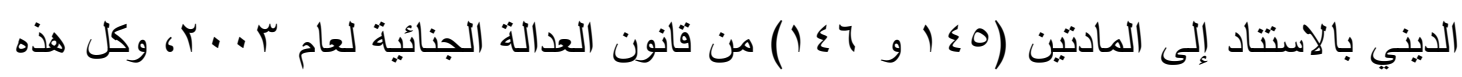
الجرائم يكون فيها المحرض بمثابة شريك في الجريمة وينساوى مع منفذها في العقوبة ذاتها. بـ

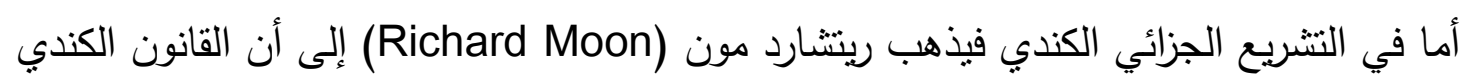
حينما يتعامل مع خطاب الكراهية والجريمة المفضية على أساسه، فهو يكفيها وفقاً لخلفية الصراع العنصري وآثار الخطابات العنصرية، وهذان الأمران يعتمد عليهما في تكييف الجريمة والعقوبة المناسبة لها.

أما في قانون العقوبات المصري فقد عدَّ المحرض شريكاً في الجريمة وفقاً للفقرة (أولاً) من المادة (• (ـ) من القانون نفسه بالنص:" كل من حرض على ارتكاب الفعل المكون للجريمة إذا كان هذا

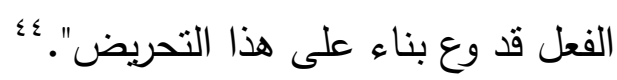
ومما تقدم يتضح ان أغلب التشريعات الجزائية الوطنية، عدت خطاب الكراهية كصورة من صور التحريض المعاقب عليه، سواء وقعت الجريمة بناءً على التحريض أم لم تقع. الفرع الثاني: الصكوك الإقليمية إن التأمل في أحكام الاتفاقيات الدولية ذات الصلة بحقوق الإنسان نجد أنها غير متماتلة في تتظيم حظر خطاب الكراهية، وقد يكون مرد ذلك إلى أنها اكتقت بوضع المعايير العليا للحقوق

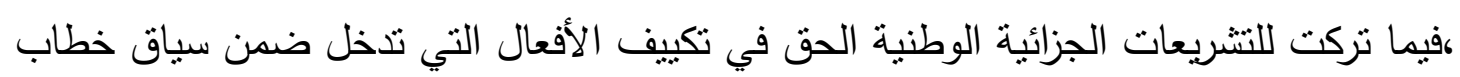

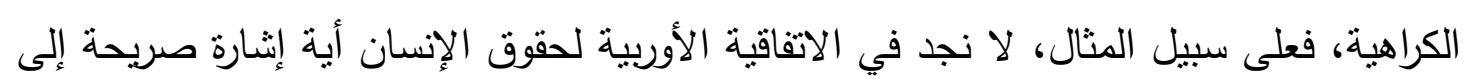
تكييف جريمة خطاب الكراهية، ؛؛ إنما تركت ذلك إلى التشريعات الجزائية الوطنية حسب ما ذكره

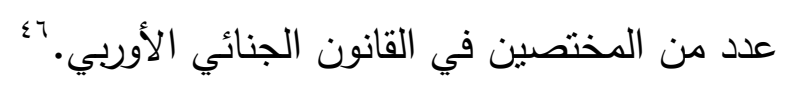
وفي ضوء السوابق القضائية للحكمة الأوربية لحقوق الكانسان، فقد ذهبت المحكمة في قضية

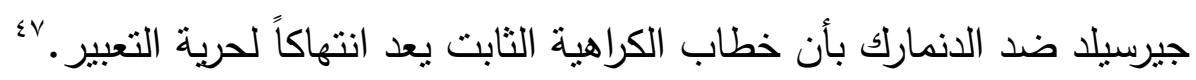


وقد نظرت المحكمة نفسها في قضية استهداف مبنى راديو وإذاعة في بلغراد من سلاح الجو التابع لحلف الثمال الأطلسي في بr نيسان ابريل من عام 1999 في أثناء حرب البلقان، وراح

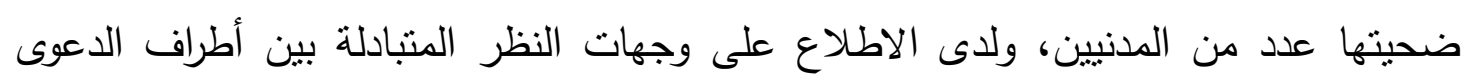
يتضح الواقع القانوني غير المستقر في ما يخص تكييف جريمة خطاب الكراهية أو التحريض

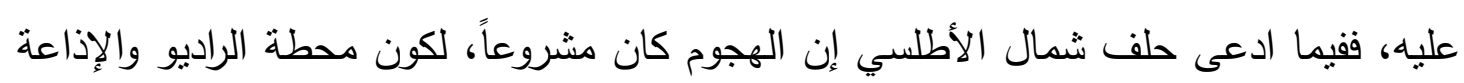

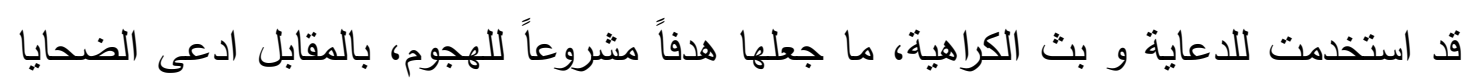

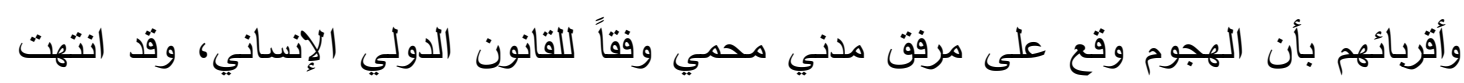
المحكمة إلى الحكم بأن المحكمة لا تملك الولاية للنظر في مثل هذه القضية لكون المدعين

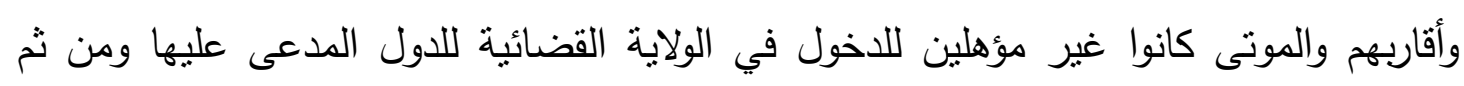
رفضت الدعوى. والأمر هذا نفسه بالنسبة للميثاق الإقريقي لحقوق الإنسان والثعوب، إذ لا نوجد أية إثنارة

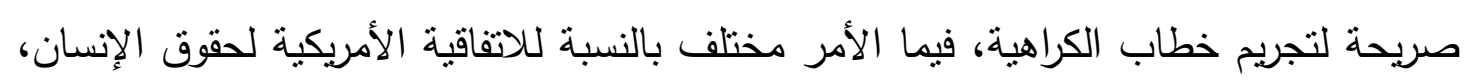
إذ أنشارت بصورة صريحة إلى تجريم خطابات الكراهية وعدتها جريمة وفقاً للفقرة (0) من المادة (ז (1) من الاتفاقية بالنص :" إن أية دعاية للحرب و أية دعوة إلى الكراهية القومية أو الدينية،

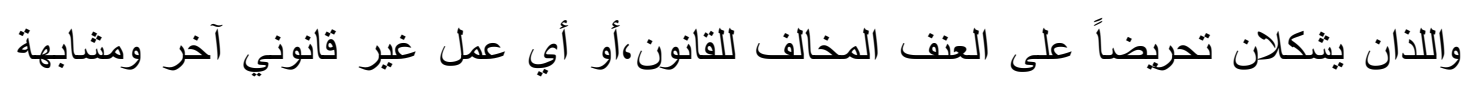
ضد أي شخص أو مجموعة أثخاص، مهما كان سببه، بما في ذلك سبب العرق أو اللون أو أو أن

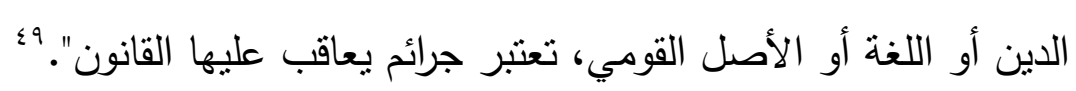

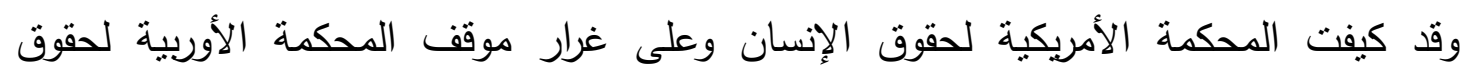
الإنسان، جريمة خطاب الكراهية بأنه إساءة لحرية الخطاب (Abuses of free speech). وختاماً يمكن القول إن فلسفة التشريعات الجزائية الوطنية تختلف نوعا ما عن فلسفة الصكوك بكاءك الإقليمية، فالحكمة من التشريعات الجزائية هي في تحقيق الأمن الداخلي وما يعنيه من استقرار الدول وأمنها، أما على الصعيد الإقليمي فالحكمة هي في تحقيق الأمن الإنساني بذاته ونعني بذللك حقه في الحياة والأمان المطلب الثاني: موقف القانون الجنائي الدولي من خطاب الكراهية في هذا المطلب سنحاول البحث عن موقع خطاب الكراهية من الأنظمة الأساسية للمحاكم الجنائية الدولية، وبعبارة أخرى هل أصابت في تتظيم خطاب الكراهية وتجريمه على نحو مستقل، 
أم أنها ذهبت لاتجاه مغاير يعكس وجهة النظر القانونية الرافضة لفكرة أن يكون خطاب الكراهية مؤسساً لجريمة بذاتها؟ هذا ما سنحاول البحث فيه والإجابة عنه في ضوء تحليل أحكام النظم

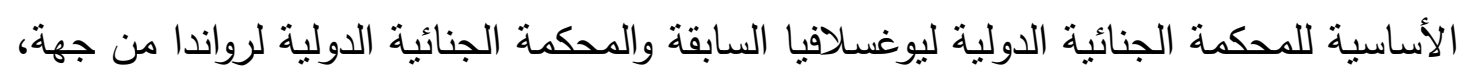
و المحكمة الجنائية الدولية من جهة أخرى، من خلال تحليل قانوني مقارن مع استقراء آراء فقهاء القانون الدولي بشأنه.

الفرع الأول: الدحاكم الجنائية الدولية (رواندا و يوغسلافيا السابقة) من الناحية الزمنية ذات الصلة بموضوع البحث، سنسلط الضوء على أهم القضايا الدولية التي رفعت أمام المحاكم الجنائية الدولية وعلى النحو الآتي:

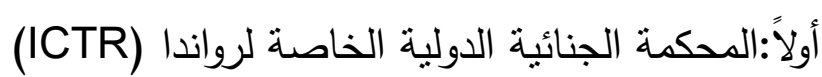

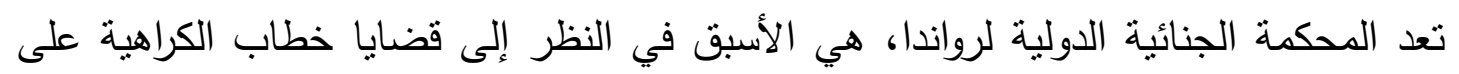
المستوى الجنائي الدولي، ولدى الاطلاع على الاجتهادات القضائية و آراء الفقهاء حيال القضايا

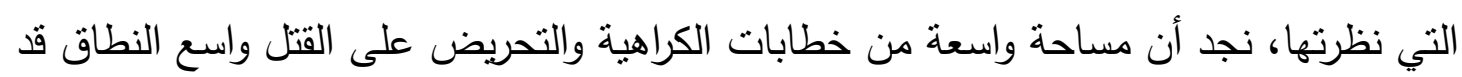
بحثت فيها المحكمة وأصدرت أحكام فيها، ومن أهم تلك القضايا ما ركز عليها فقهاء كثر سنحاول بيان توجهاتهم بالمقارنة مع نوجهات المحكمة نفسها، ومن أولئك كريكوري جوردن الذي تطرق إلى عدد من القضايا ومنها قضية الددعي العام ضد اكاييسو (Akayesu)، المتهم بتحريض مسلحي الهوتو بارتكاب مذبحة ضد سكان مدن التوتسي، وقضية المدعي العام ضد كامباندا (Cambanda) المتهم بالتحريض على قتل المدنيين وتتثبيهـون بالكلاب المتعطنة للاماء من جهة ، وتهنئته الصريحة والمباشرة لما قام به مسلحو الهوتو لإبادتهم التوتني" من Nahimana ) أخهة أخرى، وقضية المدعي العام ضد ناهيمانا وبارايكويزا ونيجيز Barayagwiza ,Ngeze,)، المتهمين باستخدام وسائل الإعلام المرئية والمسموعة والمقروءة

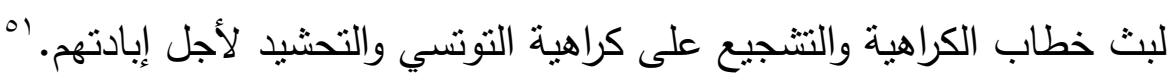
وفي تحليل هذه التهم تنشير وبيكي تنمرمان (Wibke Kristin Timmermann) بالقول :" لقد بحثت المحكمة وبالاستتاد إلى الفقرة (1) من المادة (؟) من النظام الأساس للمحكمة حيال

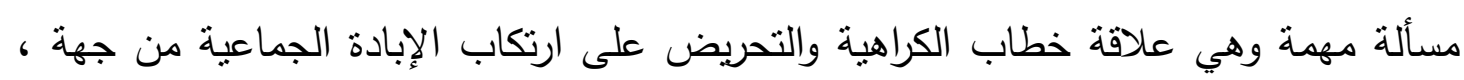

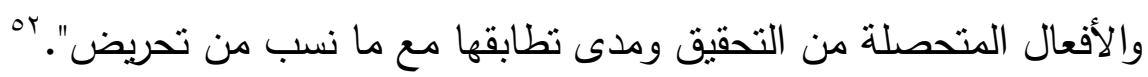


وقد يتبادر إلى الذهن حيال التكييف القانوني لما نُبِبَ إلى المتهمين من أفعال التحريض وأية

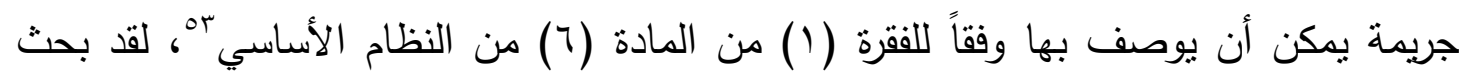
عدد من الفقهاء في هذه المسألة وكانت مرجحة بين جريمة الإبادة الجماعية وبين جريمة ضد الد الدان الإنسانية.

ومن أولئك الذين اعنرضوا على وصف هذه الأفعال بأنها جريمة ضد الإنسانية، جوزيف ريكوف (Joseph Rikhof)

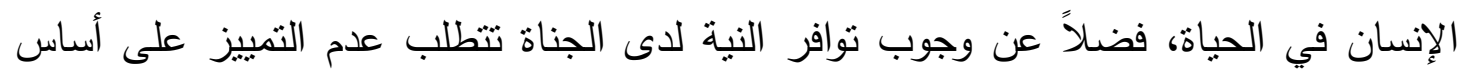
العرق، وهو ما لم يحصل في القضايا المنسوبة إلى المتهمين الذين كانت لديهم نوايا تمبيزية بقتل مجموعة محددة على أساس عرقي". \& أن هذا التوجه يؤيده فاستو بوكار (Fausto Pocar). "ويدعمه ماركو ساسولي وأنطوان بوفييه بقولهما :" .. إن الجرائم ضد الإنسانية يمكن أن ترتكب ضد المدنيين من نفس جنسية الجاني أو

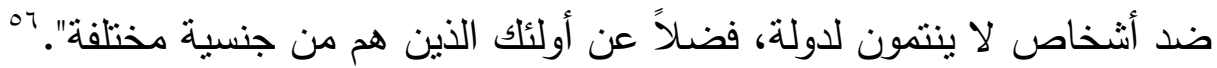
أما القاضي الأسبق انطونيو كاسيزي فيذهب باتجاه معاكس، وبعبارة أخرى أن الإبادة الجماعية يمكن أن تعد جزءاً لا يتجزأ من جريمة ضد الإنسانية في بعض الأحيان، وذلك بالاستتاد إلى له قضية المدعي العام ضد اكاييسو عند تفسير مصطلح الإفناء (Extermination) وعدّهُ جزعاً من جريمة ضد الإنسانية، إذ يقول:" أثنارت المحكمة إلى أن النظام الأساسي للمحكمة الجنائية الدولية ينص على الإفناء قد يشتمل على أفعال " آيلة إلى تدمير جزء من السكان" أي عدد إلى إلى إنها محدود من الضحايا، غير أن القانون العرفي الدولي ينص على أن الإفناء يودي بحياة عدد كبير من الضحايا".٪ه

ويختتم توماس دايفيس (Thomas E. Davies) ما أكده الفقهاء سابقاً، بالقول :" أن جريمة الإبادة الجماعية لم تجرم لذاتها بل هنالك تصرفات من شأنها أن تكون محلاً للتجريم كذللك، فالتعبير الصريح أو المبطن والذي يدعو إلى بث الكراهية ، وأن تجريم خطاب الكراهية لذاته يحقق هدفين الأول في إبلاغ أولئك الأفراد الذين أسهوا في وقوع جريمة الإبادة الجماعية على الى سبيل المثال الصحفي الثهير حسن نجيزي الذي سمم عقول قراءه بكلمات نسببت بمقتل الآلاف من المدنيين في رواندا بأنه لن يمر بدون عقاب، أما الثاني ففي منح المجتمع الدولي الفرصة لمحاولة منع وقوع إبادات جماعية في المستقبل تسبب بها أفراد عن طريق خطابات الكراهية".هـ 
أن الخلاف حيال خطاب الكراهية وفيما إذا كان سلوكا مساهما (التحريض) في ارتكاب جريمة دولية وبالذات الإبادة الجماعية، إنما يعود إلى المفاوضات التي جرت في أثناء إعداد مسودة اتفاقية منع الإبادة الجماعية والمعاقبة عليها لعام 9 19 1، إذ صرحت وفود آنذاك ومنها الوفد

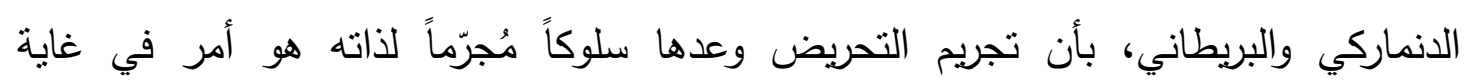

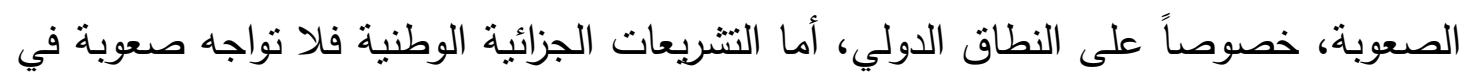
ذللك وبالتالي لا بد من عدم الفصل بين خطاب الكراهية وبين السلوك المادي المترتب عليه كأساس للتجريم. ثانياً: المحكمة الجنائية الدولية ليوغسلافيا السابقة

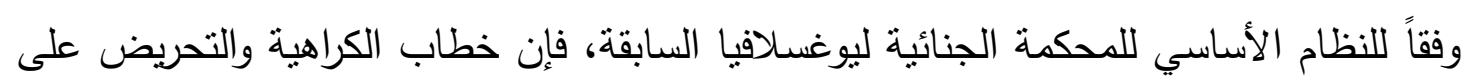

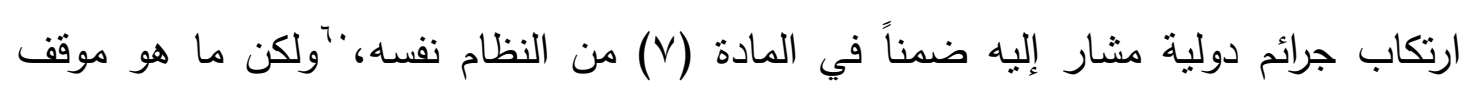

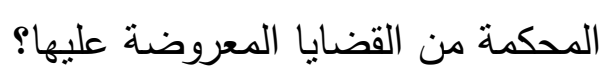
فعلى سبيل المثال ذهبت المحكمة في قضية المدعي العام ضد كورديك (Kordic) إلى اجتهاد

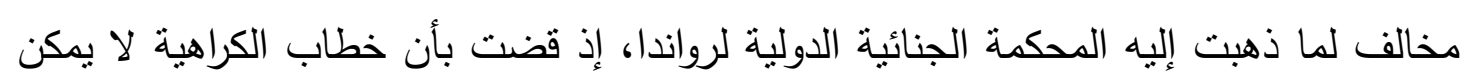

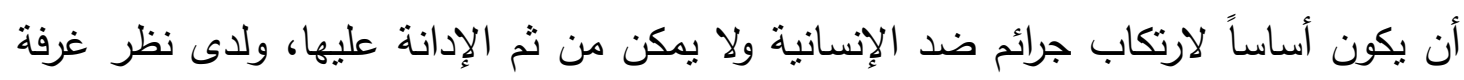
الاستئناف بحكم الدائرة الابتدائية للمحكمة، وجدت أن خطاب الكراهية إذا كان في سياق أعمال أخرى تشكل مع بعضها البعض حملة لاضطهاد مدنيين، حينها فقط بمكن أن تكون أساساً

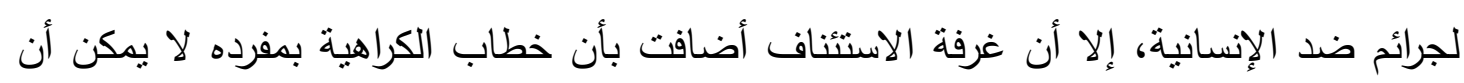

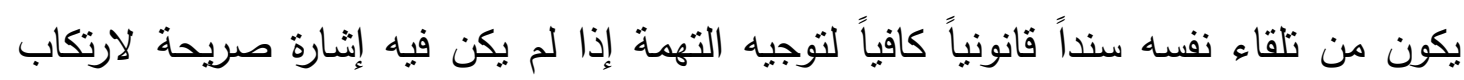

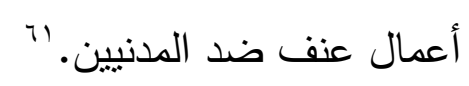
وفي اتجاه آخر وبالاستتاد إلى وجهات نظر فردية لبعض القضاة في المحكمة، يكثف عن اختلاف جوهري حيال مفهوم خطاب الكراهية، ففيما يرى القاضي الأسبق تيودور ميرون (Theodor Meron)

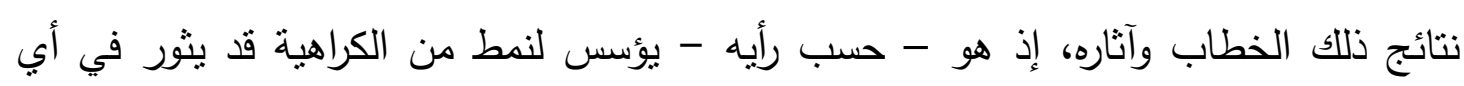

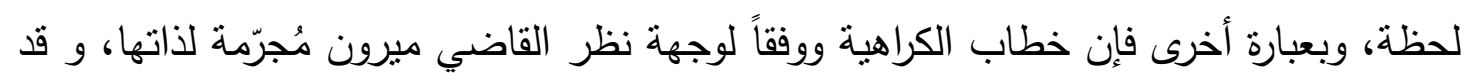
خالفه هذا الرأي القاضي الأسبق محمد شهاب الدين، إذ رأى أن خطاب الكراهية لم يحتل إلا

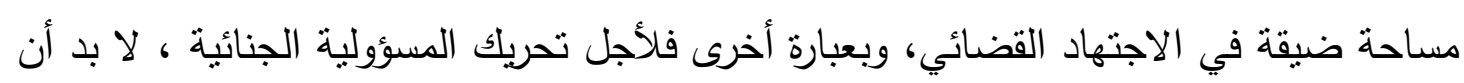


يثبت للمحكمة أن خطاب الكراهية كان مؤثراً وفاعلاً في ارتكاب الجريمة الدولية وليس

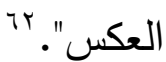

\section{الفرع الثاني : المحاكم الجنائية الدولية}

في هذا الفرع سنحاول البحث عن مسألة جوهرية تتلخص بالآتي: ما هو موقف نظام روما الأساس للمحكمة الجنائية الدولية من خطاب الكراهية؟ هل أعاد التأكيد على التحريض لارتكاب الجرائم الدولية الواردة في المادة (0) منه على الطريقة نفسها الواردة في النظامين الأساسيين للمحكمة الجنائية الدولية ليوغسلافيا السابقة والمحكمة الجنائية الدولية لرواندا؟ أم أن للمحكمة الجنائية الدولية وجهة نظر أخرى ؟ الجهابه للإجابة نقول : أن الرجوع إلى نص المادة (0)" من النظام الأساس للمحكمة الجنائية الدولية ، سنجد أنها نطرقت إلى جرائم بالتحديد دون أن تذكر التحريض ومن صوره خطاب الكراهية كجريمة مستقلة، فما هو السبب في هذا التوجه ؟ أليس التحريض على ارتكاب جريمة دولية يمنل تحدياً يهدد بذاته المجتمع الدولي بأسره، خصوصاً إذا اتخذ صورة خطاب يثير الكراهية ويحفز

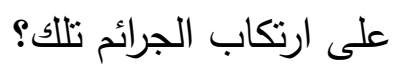
إن الملفت للنظر أن النظام الأساسي للمحكمة الجنائية الدولية اتخذ منهجاً مغايراً لما استقر عليه في النظامين الأساسيين لمحاكم يوغسلافيا السابقة و رواندا، واللذين أعطيا ولاية للمحكتين بملاحقة مرتكبي جرائم التحريض كجريمة مستقلة. لقد علق على ذلك عدد من المختصين بالقول :" إن النظام الأساسي لم يذكر جريمة التحريض كجريمة مستقلة ولا كصورة من صور المساهمة في ارتكاب الجريمة وبالخصوص جريمة الإبادة الجماعية التي جاءت بها المادة (؟) من النظام الأساس نفسه، والتي خلت من ذكر صورة التحريض على ارتكاب جريمة الإبادة الجماعية". ؟

وينتقد ماركو ساسولي وأنطوان بوفييه هذا التوجه بالقول :" نظرية المساعدة والتحريض في القانون الجنائي الدولي كما أنثارت في السوابق القضائية الدولية، فإن المساعدة في ارتكاب جريمة أو التحريض على ارتكابها تتطوي على قيام شخص ( الثريك في الجريمة ) بتقديم

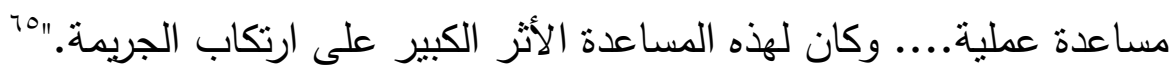

فيما أكد البعض الآخر ومنهم ويبكي تيمرمان (Wibke Kristin Timmermann) بالقول :" أن تحرك المحكمة الجنائية الدولية ضد المتهمين في ارتكاب جرائم دولية، إنما يتوقف على أثر 
هؤلاء في الجريمة ككل أو في جزء منها ، وبعبارة أخرى لا يمكن تحريك المسؤولية الجنائية

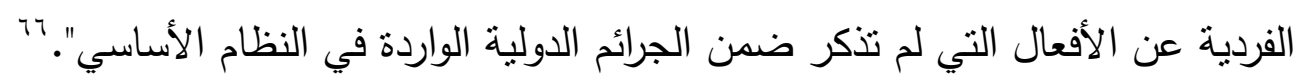
أما كريكوري جوردن (Gregory S .Gordon) فيعلق على ذللك بالقول:" أن المحكمة الجنائية الدولية و وفقاً لنظامها الأساسي لاحقت لوبانغا بسبب اتهامه بتجنيد الأطفال، دون أن تبحث المحكمة نفسها في التهم الأخرى ذات الصلة بالتحريض عن طريق إثارة خطاب الكراهية".. ومما تقدم ينضح إن عدم النص على خطاب الكراهية ضمن أحكام النظام الأساسي للمحكمة الجنائية الدولية وبالذات المادة (ך) منه، هو بسبب عدم تقبل فكرة أن يكون خطاب التحريض بذاته سبباً لقيام المسؤولية الجنائية الفردية ، إذ يشير كل من جاكوبس (Jacobs) و بوتر إلى أنه ولكي يكون خطاب الكراهية مُجرّماً، فلا بد من إثبات أن الخطاب كان منحيزاً (Potter) (Prejudice)

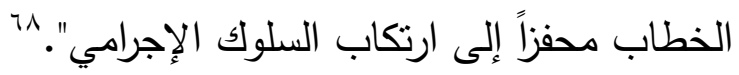
وهو ما انتقده انطونيو كاسيزي بالقول:" ويترتب على ذلك أقله في مجال واحد، وجود تناقض بين القانون الدولي العرفي والنظام الأساسي للمحكمة الجنائية الدولية، فالأول يحظر ويعاقب " التآمر لارتكاب جريمة الإبادة الجماعية الذي يشكل جريمة غير تامة تشتمل على التخطيط للإبادة

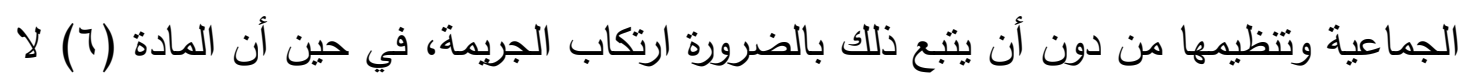

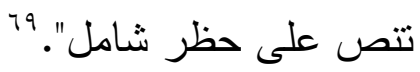
إن مراجعة أحكام النظام الأساسي للمحكمة الجنائية الدولية وبالذات الأحكام ذات الصلة بخطاب الكراهية كصورة من صور التحريض، ليبين أن النظام الأساسي للحككة ، وبالفعل لم يشر إلى لى حكم صريح ومباشر لعد خطاب الكراهية كجريمة مستقلة، بل عدّها من ضمن الأفعال التي تتطلب تزامناً مع فعل إجرامي آخر يقترف، وبعبارة أخرى لكي يكون الخطاب بحد ذاته كصورة

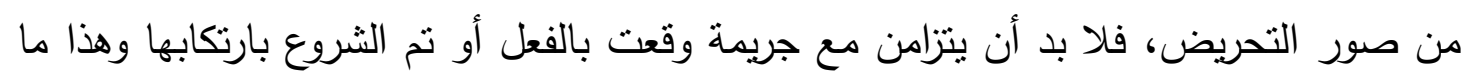

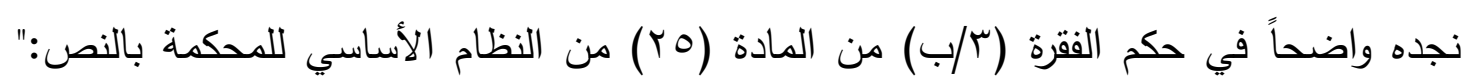

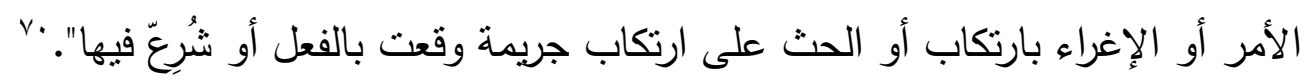
وبالإثارة إلى واقع النظام الأساسي للمحكمة نستذكر ما قاله ماركو ساسولي وأنطوان بوفيبه تعليقاً على خطورة خطاب الكراهية بالقول:" .. أن خطاب الكراهية والمعلومات المضللة والحملات الإعلامية العدائية لا تزال تستخدم كأدوات صماء ضد المدنيين، مثيرة للعنف العرقي بالي 
ومجبرة على النزوح ولذلك فإن منع هذه الأنشطة وكفالة نشر المعلومات الدقيقة يشكلان جزءاً

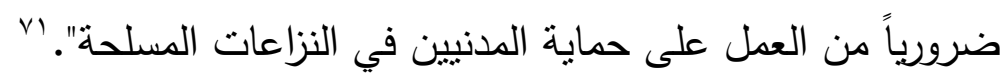
ويمكن القول إن وجهة النظر المنقدمة تعكس اختلاف الدذاهب القانونية المعنية بتكييف جريمة خطاب الكراهية، القائم بالأساس على الاختلاف في تحديد صور التحريض والعقوبة عليها، ففي أغلب التنريعات الجزائية الوطنية وكما اتضح سابقاً في هذا البحث، تنظر إلى خطاب الكراهية بكونه جريمة مستقلة تدخل ضمن صور التحريض سواء وقعت الجريمة أم لم تقع، على عكس إنس توجهات القانون الجنائي الدولي الذي نراوح بين رأيين يذهب الأول إلى التجريم الذاني لخطاب

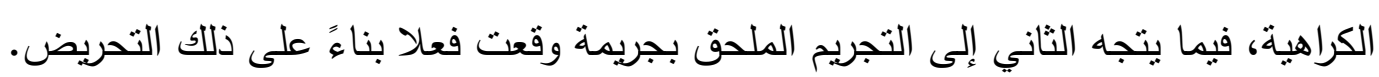
لقد ركز عدد من الباحثين ومنهم ديفيد براكس (David Brax) وكريسنيان مونث ( Christian

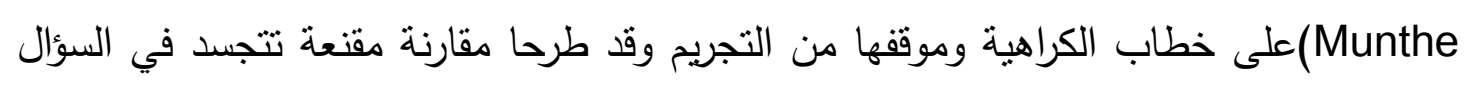

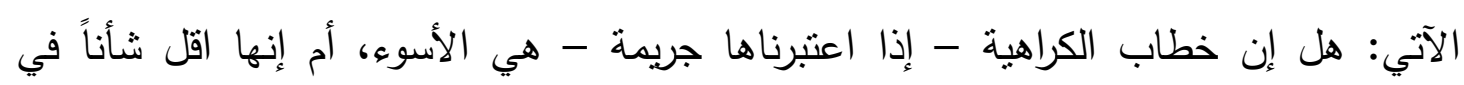
الضرر بالقياس إلى جرائم أخرى؟ الاب؟ هل

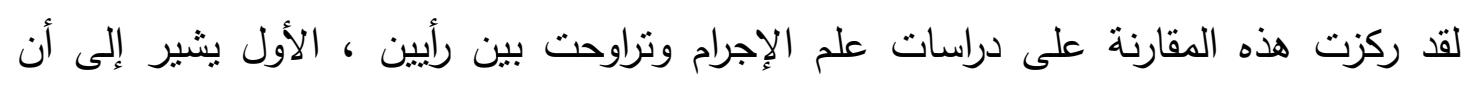

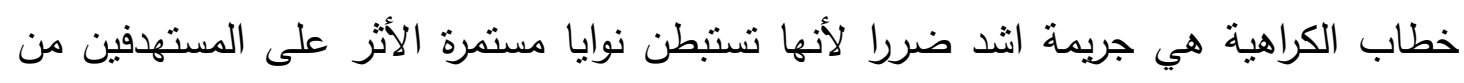
الخطاب، فيما يذهب آخرون إلى أنها ليست بهذا السوء والمبالغة في التجريم، إذ أنها مسألة وقتية يمكن أن تتتهي بمجرد المصالحة بين الأطراف العرقية، فيما ستكون الجرائم الأخرى

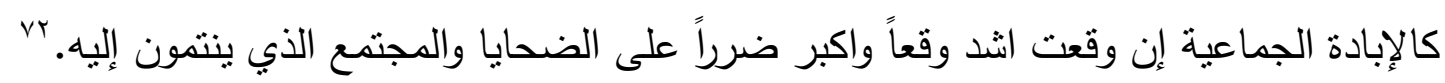
وفي هذا المجال يمكن القول إن الرأي الأول هو الأقوى وبدليل قرآني صريح إذ يشير الله تعالى

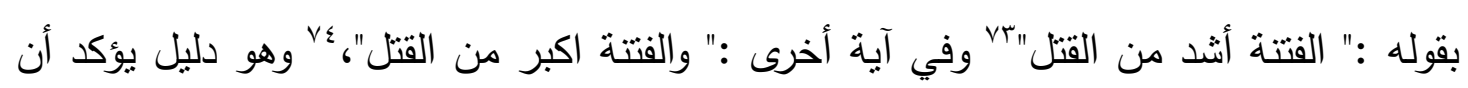
خطاب الكراهية كصورة من صور الفتتة لأثد من القتل نفسه.

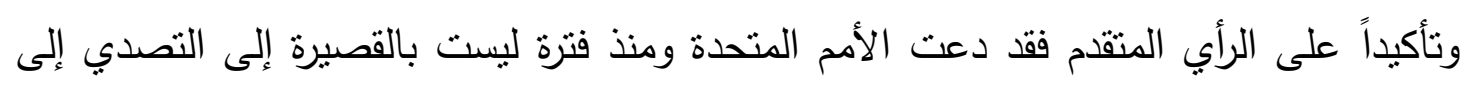

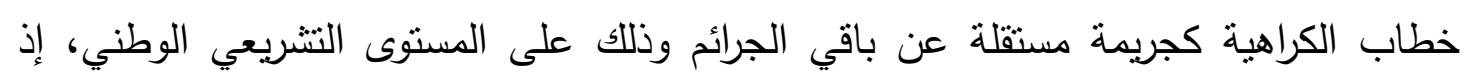
أنثارت الفقرة (1) من برنامج الأمم المتحدة والخاص بمنع التحريض إلى :" ويعتبر إنفاذ

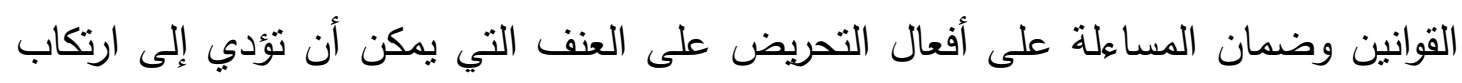

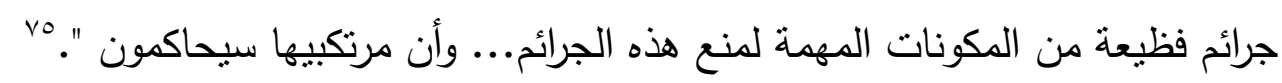


بعد أن بينا جانباً مهماً من مفهوم خطاب الكراهية و موقف الصكوك الدولية منها، فضلاً عن القانون الجنائي الدولي واجتهادات المحاكم الجنائية الدولية، فقد توصل البحث إلى عدد من

النتائج والتوصيات وهي كالآتي:

النتائج

ا. إن مراجعة الفظائع التي ارتكبت أو التي يجري ارتكابها في عالم اليوم، لتتبت أن النزاعات

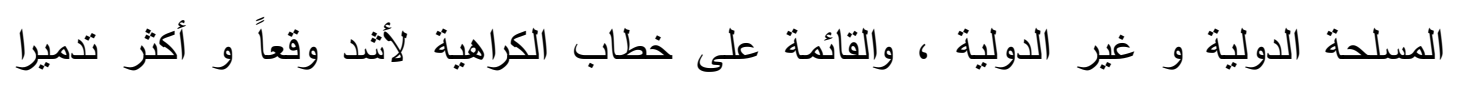
للإنسانية، بالمقارنة مع مثيلاتها من النزاعات التي يتقابل فيها طرفان متحاربان هدف الواحد منهما نيل النصر والظفر بالمعركة وهزيمة الطرف الآخر ، بدلا من إفناءه وتدميره كلياً. r. لقد ثبت بالواقع أن قيام الآلاف من المتورطين في مذابح جرت في دول كرواندا ويوغسلافيا

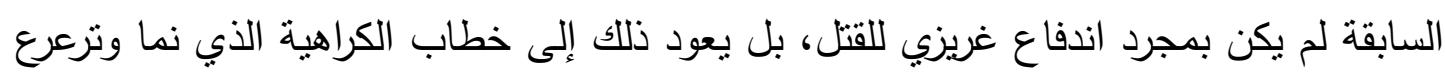
في مجتمع واحد عن طريق وسائل الإعلام وغيرها من الوسائل الأثند نأثيرا لدى المتلقين.

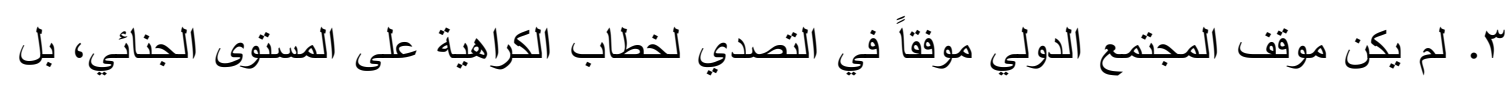

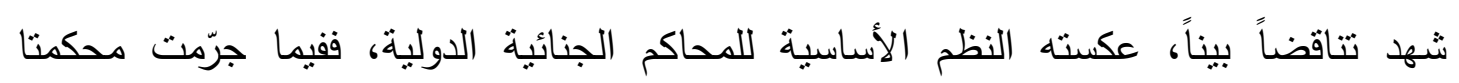

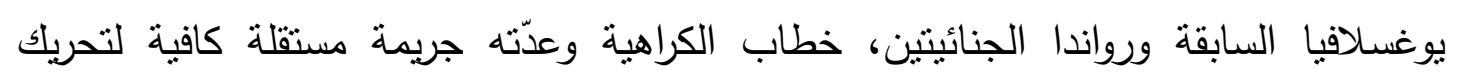

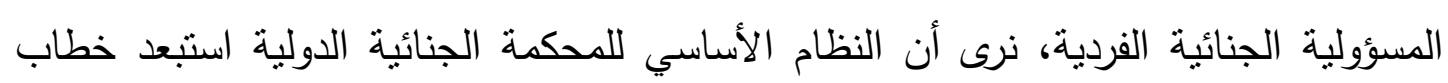

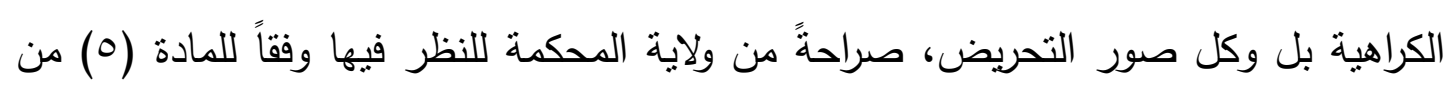
النظام الأساسي نفسه، ما لم يكون خطاب التحريض متعلقاً بجريمة وردت على سبيل الحصر في المادة نفسها.

ع. إن تجريم خطاب الكراهية على المستوى الدولي له الأثر الفعال في بيان موقف هذا المجتمع من جريمة خطاب الكراهية ، وتعكس عدم تحيزه لموقف الجناة، فضلا عن أنه تعبير صريح وفعال لاستتكار هذا التصرف غير السوي الواجب معاقبته بأثند العقوبات.

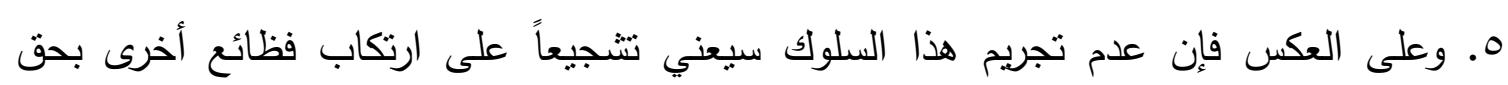

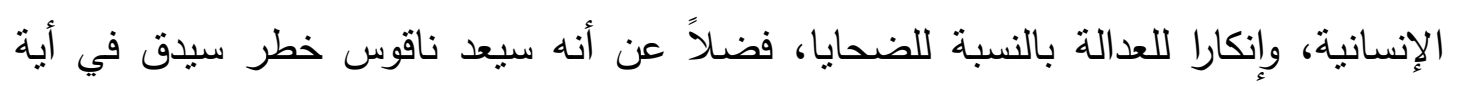
لحظة مخلفة وراء ذلك المزيد من النزاعات المسلحة القائمة على الكراهية وإنشاعة البغضاء بين بني البشر. 
7. و أخيراً يفترض و على نحو مقنع أن من أهم أهداف تتكيل الدحاكم الجنائية الدولية هو التلويح بالجزاءات كإجراء ردعي (Preventive Measure). وفي هذه النقطة لم يكن النظام الأساس للمحكمة الجنائية الدولية موفقاً في استبعاد التحريض صراحة وخطاب الكراء الكراهية ضمناً من الجرائم التي تخضع لولاية المحكمة،إذ إن ذلك سيعني استعداد افراد أو مؤسسات بإثارة مجتمعات تثهد نتوعاً عرقياً على سبيل المثال، لتنقاتل فيما بينها ضاربة مبادئ دولية إنسانية

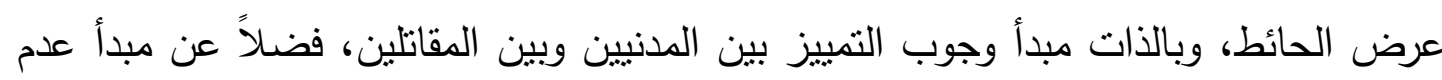
جواز ارتكاب الآلام التي لا مبرر لها. توصية

ا. على الدول كافة تثريع قوانين جزائية تلاحق المتهمين بارتكاب سلوك خطاب الكراهية، وعلى نحو فعال و واضح، دون أن يؤدي ذللك إلى التعارض مع المبادئ ذات الصلة بحرية التعبير . r. تعديل النظام الأساسي للمحكمة الجنائية الدولية، بما يتيح للأخيرة القدرة على التعامل مع جريمة خطاب الكراهية وبهيأة جريمة مستقلة لذاتها، ويكون ذلك عن طريق معالجة النصوص الواردة في النظام ، ولاسيما المادة (ro) منه ورفع صور التحريض الواردة فيه كجريمة ملحقة لما ورد في المادة (0) من النظام نفسه. r. تعديل المادة (0) من النظام الأساسي وإضافة جريمة سادسة وهي جريمة التحريض، المنضمنة صراحة أو ضمناً الإثارة إلى خطاب الكراهية كجريمة مستقلة لا ربطها بجريمة الإبادة الجماعية على النحو الحالي للنظام الأساسي للمحكمة الجنائية الدولية. 


\section{الهوامش}

$$
\begin{aligned}
& \text { ' أبو الفضل جمال الدين محمد بن منظور ، لسان العرب، المجلد الأول، ص، البَّ. }
\end{aligned}
$$

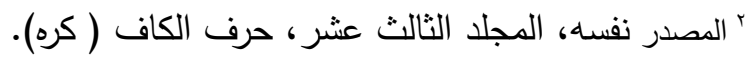

${ }^{3}$ http://www.dictionary.com/browse/hate-speech

4 http://dictionary.cambridge.org/dictionary/english/hate-speech

ه الأمم المتحدة، الجمعية العامة، التحريض على الكراهية العنصرية والدينية وتعزيز التسامح، تقرير المفوضة

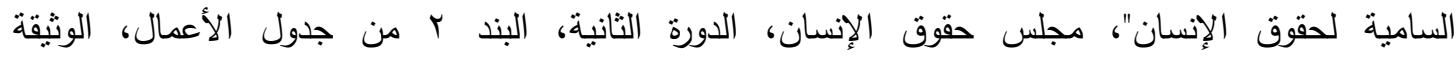
. A/HRC/2/6 20 September 2006

${ }^{6}$ Yulia A. Timofeeva, Hate Speech Online: Restricted or Protected? Comparison of Regulations in the United States And Germany ",j. Transitional Law and Policy Review,Vol.12:2,Sipring 2003,p,257,

7 Mafeza Faustin," Preventive Genocide by Fighting Against Hate Speech", International Journal of Advanced Research, Vol/4.Issue.3,2016,p,118.

8 http://www.abouna.org/content/\%D9\%85\%D8\%A7-\%D9\%87\%D9\%88-

\%D8\%AE\%D8\%B7\%D8\%A7\%D8\%A8-

\%D8\%A7\%D9\%84\%D9\%83\%D8\%B1\%D8\%A7\%D9\%87\%D9\%8A\%D8\%A9\%D8\%9

$\mathrm{F}$

${ }^{9}$ Mafeza Faustin, op.cit.p. 118.

10 http://www.un.org/ar/documents/udhr/

11 http://hrlibrary.umn.edu/arab/euhrcom.html

12 http://hrlibrary.umn.edu/arab/am2.html

r' العهد الخاص بالحقوق الددنية والسياسية لعام 974 1، منشور على موقع مكتبة جامعة منيسوتا الأمريكية في

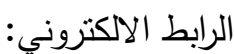

http://hrlibrary.umn.edu/arab/b003.html

${ }^{14}$ Anne Weber," Manual On hate Speech", Council of Europe Publishing, 2009, p.3.

15 Ivana Tucak," Analysis of freedom of Speech", Jura A Pecsi tudomanyegyetem Allam, 2011, p.133.

16 Wibka Kristin Timmermann," Incitement in International Criminal Law", IRRC, Vol.88, No.864, Decmeber 2006, p.837.

17 UN, Study on International Standard Relating to Incitement to Genocide or Racial Hatred", UN Special Advisor on the Prevention of Genocide, 2006, p.25. 
18 Ibid, p.25.

19 Thomas E. Davis, op.cit.p.245.

20 https://www.icrc.org/ara/resources/documents/misc/62sgrn.htm

21 Wibke Kristin Timmermann," Incitement, Instigation, Hate Speech and War propaganda in International Law", p.25.

r r ماركو ساسولي و أنطوان بوفييه ،" كيف يوفر القانون الحماية في الحرب ؟ : مختارات من القضايا الخاصة

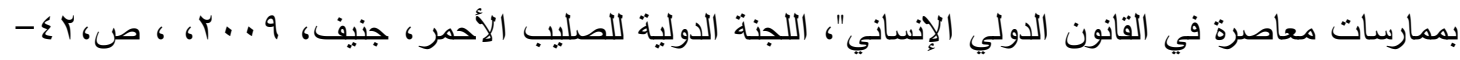

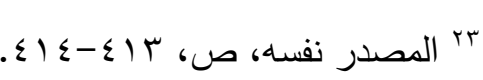

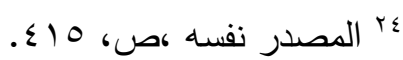

${ }^{25}$ Gregory S .Gordon," Formulating a new atrocity Speech Offences: Incitement to Commit War Crimes ", Loyola University Chicago Law Journal, Vol.43, 2012 .p. 281 .

צr جان بكتيه، "القانون الدولي الإنساني تطوره ومبادئه"، معهد هنري دونان، جنيف ع 9 (اص. Y I.

27 Gregory S .Gordon,op.cit, p.303.

28 Ibid, p.304.

29 Ibid.p. 284.

${ }^{30}$ Wibke Kiristin Temmerman, op.cit.p.84.

31 Ibid.84.

rr اللجنة الدولية للصليب الأحمر ، اللحقان (( البرتوكولان)) الإضافيان إلى اتفاقيات جنيف المعقودة في rآ آب

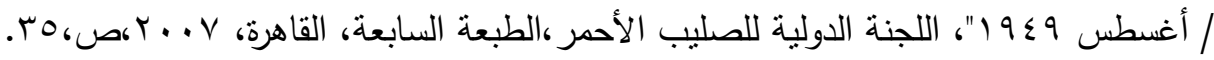

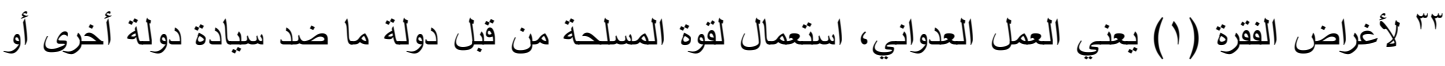
سلامتها الإقليمية أو استقلالها السياسي أو بأي صورة أخرى تثتافي مع ميثاق الأمم المتحدة...سواء بإعلان

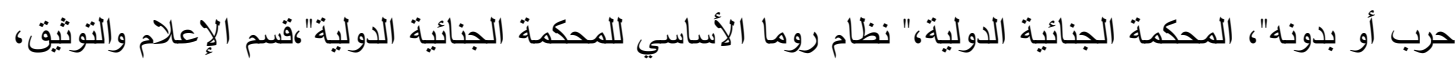

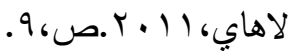
گَ" أحمد عزت، فهد البنا و نهاد عبود،" خطابات التحريض وحرية التعبير " الحدود الفاصلة"، مؤسسة حرية الفكر والتعبير ، القاهرة،ص، ع. 35 OSCE," Hate Crimes Law: A practical Guide ", OSCE ,Office for Democratic Institute and Human Rights, Warsaw Poland,2009,p.19.

$$
\begin{aligned}
& \text { r" ماركو ساسولي وأنطوان بوفييه، ص، 90-97. } 97 .
\end{aligned}
$$

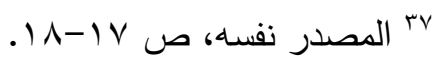

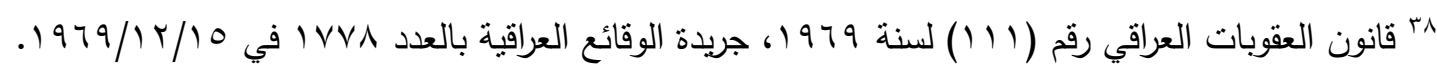




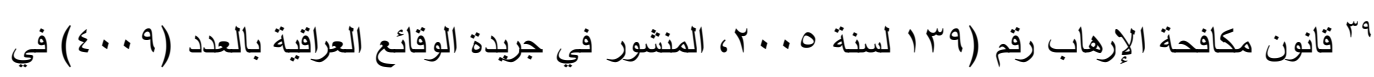

$$
\begin{aligned}
& . r .0 / 11 / 9 \\
& \text { •" المصدر نفسه. }
\end{aligned}
$$

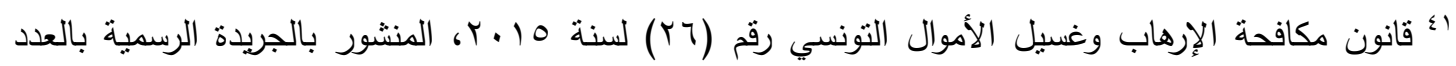

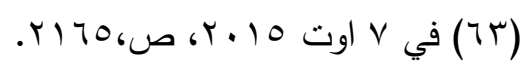

42 U.K," Hate Crime: The Case for Extending the Existence Offences", Appendix A: Hate Crime and Freedom of Expression under the European Convention on Human Rights: Law Commission, Consultation Paper No.213, Crown Copyright, 2013, p.1. ${ }^{43}$ Richard Moon, "Hate Speech Regulation in Canada", Florida State University Law Review, Vol.36:79, 2008, p.84.

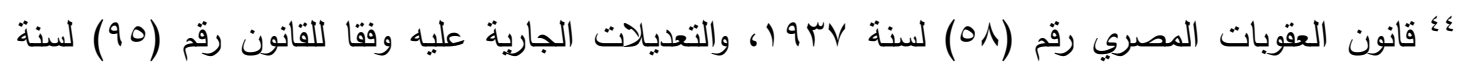

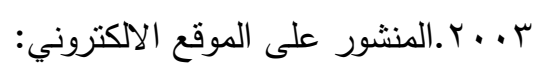
http://www.abonaf-law.com/download/GalleryServices/35_law\%201.pdf

45 Wibke Kristin Timmermann, op.cit.p.56.

46 Sarah Summers, Christian Schwarzenegger, Gian Ege and Finaly Young, the emergence of eu criminal law", Oxford and Portland, Oregon, Hart publishing, 2014, pp.74-75.

47 Wibke Kristin Timmermann, op.cit.p.57.

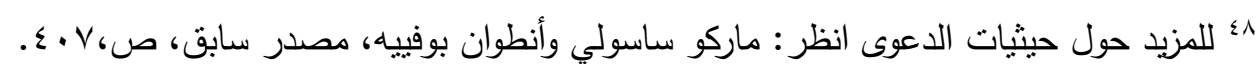

49 http://hrlibrary.umn.edu/arab/am2.html

50 Wibke Kristin Timmermann, op.cit.p.58.

51 Gregory S. Gordon, op.cit.pp.292-293.

52 Wibke Kristin Timmermann," Incitement in international Criminal Law", op.cit.p.839.

ror نصت الفقرة (1) من المادة (؟) من النظام الأساسي بأنه :" الشخص المخطط ، المحرض، الآمر لارتكاب

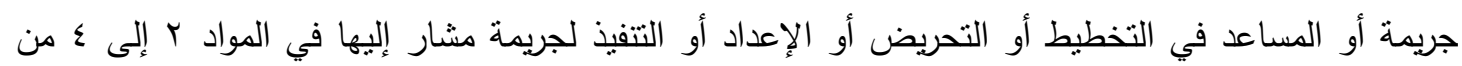
النظام الأساسي، يكون مسؤولا شخصيا عن الجريمة"، انظر النظام الأساسي للمحكمة الجنائية الدولية لرواندا

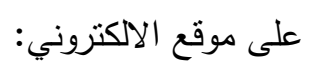

http://unictr.unmict.org/sites/unictr.org/files/legal-

library/100131_Statute_en_fr_0.pdf

54 Joseph Rikhof," Hate Speech and International Criminal Law", Journal of International Criminal Justice, Vol.3, 2005, p.1128. 
55 Fausto Pocar," Persecution as a Crime under International Criminal Law", Journal of National Security Law and Policy, Vol.2:355, 2008, p.361.

$$
\text { ro ماركو ساسولي وأنطوان بوفييه، مصدر سابق، }
$$

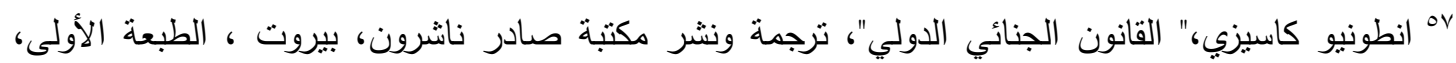

58 Thomas E.Davies," How the Rome Statute Weakens the International Prohibition on Incitement to Genocide", Harvard Human Rights Journal, Vol.22, 2009, p.245.

59 Wibke Kristin Temmermann," Incitement in International Criminal Law", op.cit.p.837.

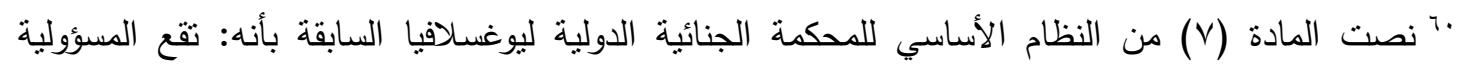

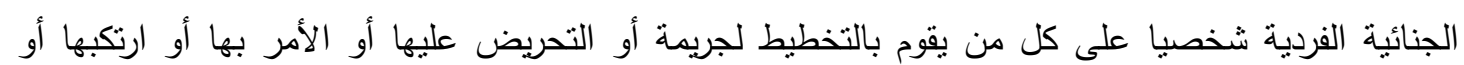

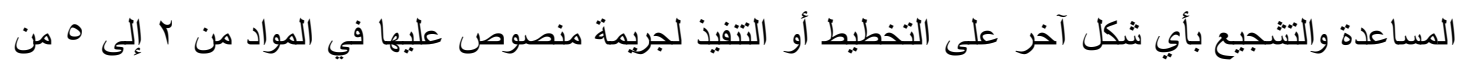

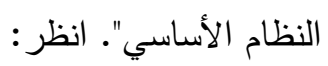
United Nations," Updated Statute of the International Criminal Tribunal for the former Yugoslavia", English and French Document, September 2009.

61 Gregory S .Gordon," The Forgotten Nuremberg Hate Speech Case: Otto Dietrich and the Future of Persecution Law", Ohio State Law Journal, Vol.75:3, 2014, p.592. 62 Ibid,pp.952-953.

זٓ نصت المادة (0) من النظام الأساسي بأنه: يقتصر اختصاص المحكمة على اشد الجرائم خطورة موضع اهتمام المجتمع الدولي بأسره، وللمحكمة بموجب هذا النظام الأساسي اختصاص النظر في الجرائم التالية: أ:

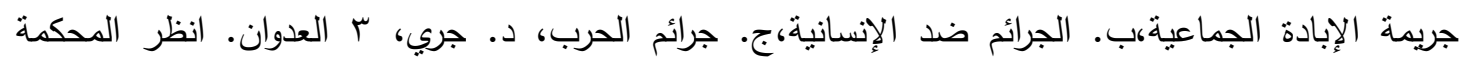

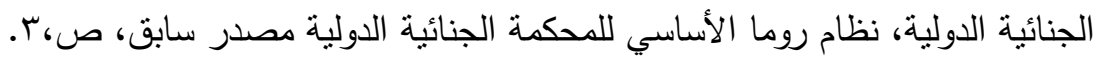

${ }^{64}$ Thomas E.Davies, op.cit.p.261.

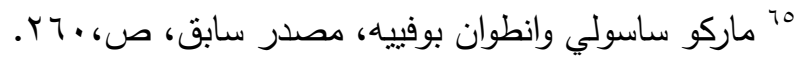

66 Wibke Kristin Timmermann, op.cit.p.74.

67 Gregory S.Gordon," Formulating a New Atrocity Speech Offence: Incitement to Commit War Crimes", op.cit.p.290.

68 Megan Sullaway," Psychological Perspectives on Hate Crime Laws", Psychology, Public Policy and law Journal, vol.10, no.3, 2004, p.251.

$$
\text { 9979 انطونيو كاسيزي، مصدر سابق، ص، ror. ror. }
$$

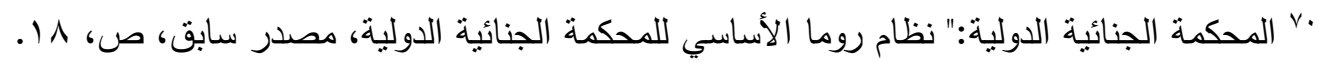

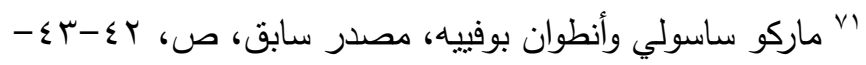


72 David Brax and Christian Munthe," the philosophy of Hate Crime anthology", University of Gothenburg, Philosophy, Linguistics and theory of Science, part 1, pp.24-25.

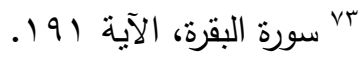

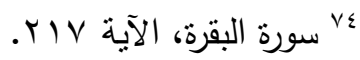
ov الأمم المتحدة، " منع التحريض: الخيارات المتاحة في مجال السياسات العامة"، متاح على الرابط الإكتروني لمألمم المتحدة

http://www.un.org/ar/preventgenocide/adviser/pdf/prevention_of_incitement_policy_o ptions.pdf

\section{قائمة المصادر}

القرآن الكريم

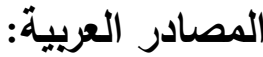

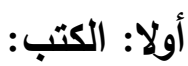

ا. أبو الفضل جمال الدين محمد بن منظور ، لسان العرب، المجلد الأول.

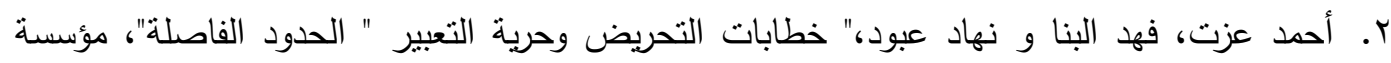
حرية الفكر والتعبير ، القاهرة.

r. انطونيو كاسيزي،" القانون الجنائي الدولي"، ترجمة ونشر مكتبة صادر ناشرون، بيروت ، الطبعة

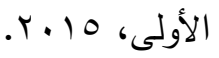

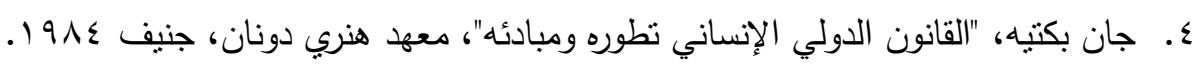

ه. ماركو ساسولي و أنطوان بوفييه ،" كيف يوفر القانون الحماية في الحرب ؟ : مختارات من القضايا الخاصة بممارسات معاصرة في القانون الدولي الإنساني"، اللجنة الدولية للصليب الأحمر، جنيف، 


\section{ثانياً: التشريعات و الصكوك والوثائق الدولية}

\section{أ- - التشريعات الوطنية}

1. قانون العقوبات العراقي رقم (111) لسنة 19791، جريدة الوقائع العراقية بالعدد IVVA في

1979/1r/10

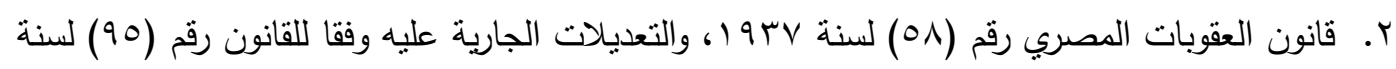

$$
\text { r... }
$$

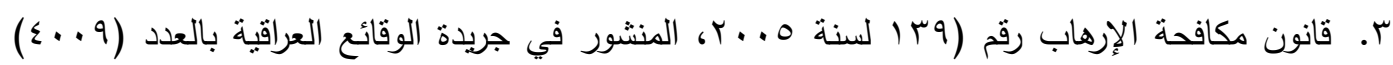

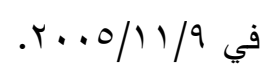

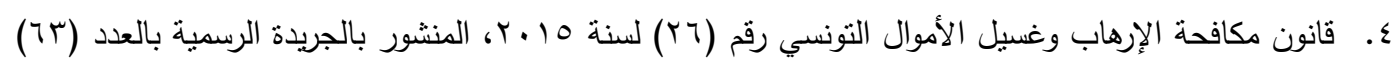

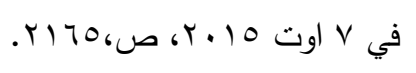

\section{ب- - ب الصكوك الدولية}

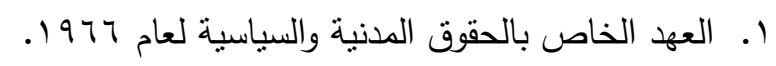
r. الاتفاقية الأمريكية لحقوق الإنسان، سان خوسيه، 1979

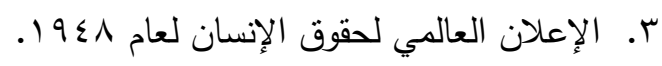

ع. اتفاقية حماية حقوق الإنسان في نطاق مجلس أوروبا ، روما في ع نوفمبر .190 (الاتفاقية الأوربية

$$
\text { لحقوق الإنسان) }
$$

ا ـ الأمم المتحدة، " منع التحريض: الخيارات المتاحة في مجال السياسات العامة. r. اللجنة الدولية للصليب الأحمر، اللحقان (( البرتوكولان)) الإضافيان إلى اتفاقيات جنيف المعقودة في

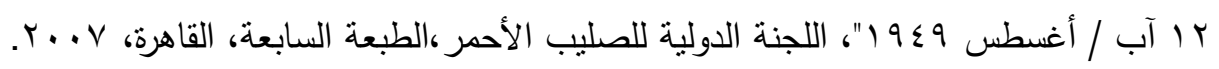
ז. المحكمة الجنائية الدولية،" نظام روما الأساسي للمحكمة الجنائية الدولية"،قسم الإعلام والتوثيق،

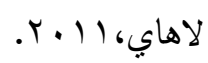




\section{References by Forging Language}

\section{First: Books}

1. Anne Weber," Manual On hate Speech", Council of Europe Publishing, 2009.

2. Ivana Tucak," Analysis of freedom of Speech", Jura A Pecsi tudomanyegyetem Allam, 2011.

3. OSCE," Hate Crimes Law: A practical Guide ", OSCE ,Office for Democratic Institute and Human Rights, Warsaw Poland,2009,p.19.

4. Sarah Summers, Christian Schwarzenegger, Gian Ege and Finaly Young, the emergence of eu criminal law", Oxford and Portland, Oregon, Hart publishing, 2014.

5. U.K," Hate Crime: The Case for Extending the Existence Offences", Appendix A: Hate Crime and Freedom of Expression under the European Convention on Human Rights: Law Commission, Consultation Paper No.213, Crown Copyright, 2013.

\section{SECOND: Researches and Studies.}

1. David Brax and Christian Munthe," the philosophy of Hate Crime anthology", University of Gothenburg, Philosophy, Linguistics and theory of Science.

2. Fausto Pocar," Persecution as a Crime under International Criminal Law", Journal of National Security Law and Policy, Vol.2:355, 2008.

3. Gregory S .Gordon," The Forgotten Nuremberg Hate Speech Case: Otto Dietrich and the Future of Persecution Law", Ohio State Law Journal, Vol.75:3, 2014.

4. Joseph Rikhof," Hate Speech and International Criminal Law", Journal of International Criminal Justice, Vol.3, 2005.

5. Mafeza Faustin," Preventive Genocide by Fighting Against Hate Speech", International Journal of Advanced Research, Vol.4.Issue.3,2016.

6. Megan Sullaway," Psychological Perspectives on Hate Crime Laws", Psychology, Public Policy and law Journal, vol.10, no.3, 2004.

7. regory S .Gordon," Formulating a new atrocity Speech Offences: Incitement to Commit War Crimes ", Loyola University Chicago Law Journal, Vol.43, 2012.

8. Richard Moon, "Hate Speech Regulation in Canada", Florida State University Law Review, Vol.36:79, 2008.

9. Thomas E.Davies," How the Rome Statute Weakens the International Prohibition on Incitement to Genocide", Harvard Human Rights Journal, Vol.22, 2009.

10. Wibka Kristin Timmermann," Incitement in International Criminal Law", IRRC, Vol.88, No.864, December 2006.

11. Yulia A. Timofeeva, Hate Speech Online: Restricted or Protected? Comparison of Regulations in the United States And Germany ",j. Transitional Law and Policy Review,Vol.12:2,Sipring 2003. 
Third: Thesis.

Wibke Kristin Timmermann," Incitement, Instigation, Hate Speech and War propaganda in International Law".

\section{Forth: Documents.}

1. UN, Study on International Standard Relating to Incitement to Genocide or Racial Hatred", UN Special Advisor on the Prevention of Genocide, 2006.

2. United Nations," Updated Statute of the International Criminal Tribunal for the former Yugoslavia", English and French Document, September 2009.

\section{Web -Sites.}

1. http://dictionary.cambridge.org/dictionary/english/hate-speech

2. http://hrlibrary.umn.edu/arab/am2.html

3. http://hrlibrary.umn.edu/arab/am2.html

4. http://hrlibrary.umn.edu/arab/b003.html

5. http://hrlibrary.umn.edu/arab/euhrcom.html

6. http://www.abonaf-law.com/download/GalleryServices/35_law\%201.pdf

7. http://www.abouna.org/content

8. http://www.dictionary.com/browse/hate-speech

9. http://www.un.org/ar/documents/udhr/

10. http://www.un.org/ar/preventgenocide/adviser/pdf/prevention_of_incitement_ policy_options.pdf

11. https://www.icrc.org/ara/resources/documents/misc/62sgrn.ht

12. http://unictr.unmict.org/sites/unictr.org/files/legal-library/100131_Statute_en_fr_0.pdf 